\title{
A Short Review on Copper Calcium Titanate (CCTO) Electroceramic: Synthesis, Dielectric Properties, Film Deposition, and Sensing Application
}

\author{
Mohsen Ahmadipour ${ }^{1} \cdot$ Mohd Fadzil Ain ${ }^{2} \cdot$ Zainal Arifin Ahmad $^{1}$
}

Received: 14 December 2015/Accepted: 7 March 2016/Published online: 30 March 2016

(C) The Author(s) 2016. This article is published with open access at Springerlink.com

\begin{abstract}
Electroceramic calcium copper titanates $\left(\mathrm{CaCu}_{3} \mathrm{Ti}_{4} \mathrm{O}_{12}, \mathrm{CCTO}\right)$, with high dielectric permittivities $(\varepsilon)$ of approximately $10^{5}$ and $10^{4}$, respectively, for single crystal and bulk materials, are produced for a number of wellestablished and emerging applications such as resonator, capacitor, and sensor. These applications take advantage of the unique properties achieved through the structure and properties of CCTO. This review comprehensively focuses on the primary processing routes, effect of impurity, dielectric permittivity, and deposition technique used for the processing of electroceramics along with their chemical composition and micro and nanostructures. Emphasis is given to versatile and basic approaches that allow one to control the microstructural features that ultimately determine the properties of the CCTO ceramic. Despite the intensive research in this area, none of the studies available in the literature provides all the possible relevant information about CCTO fabrication, structure, the factors influencing its dielectric properties, CCTO immobilization, and sensing applications.
\end{abstract}

Keywords CCTO $\cdot$ Chemical synthesis $\cdot$ Dielectric permittivity $\cdot$ Loss factor $\cdot$ Deposition $\cdot$ Sensitivity

\section{Introduction}

Calcium copper titanate (CCTO) has the chemical formula of $\mathrm{CaCu}_{3} \mathrm{Ti}_{4} \mathrm{O}_{12}$, a novel electroceramic material with high dielectric permittivity $(\varepsilon)$, of approximately 100,000 for single crystal and 10,000 for bulk material at room temperature. In addition, CCTO shows moderate dielectric loss ( $\tan \delta \sim 0.15)$ at a broad frequency region (up to $10^{6}$ $\mathrm{Hz}$ ), high positive temperature coefficient of resonant frequency $\left(\tau_{\mathrm{f}} \sim+9.13 \mathrm{ppm} \mathrm{K} \mathrm{K}^{-1}\right)$, and phase transition stability against temperatures of a wide range

Zainal Arifin Ahmad

srzainal@usm.my

$1 \quad$ Structural Materials Niche Area, School of Materials and Mineral Resources Engineering, Universiti Sains Malaysia, Engineering Campus, 14300 Nibong Tebal, Penang, Malaysia

2 School of Electrical and Electronic Engineering, Universiti Sains Malaysia Engineering Campus, 14300 Nibong Tebal, Penang, Malaysia
(100-400 K). In 2000, Subramanian et al. [1] discovered that CCTO belongs to the family of $\mathrm{ACu}_{3} \mathrm{Ti}_{4} \mathrm{O}_{12}(\mathrm{~A}=\mathrm{Ca}$, $\mathrm{Sr}, \mathrm{Ba}, \mathrm{Bi}_{2 / 3}, \mathrm{Y}_{2 / 3}, \mathrm{La}_{2 / 3}$ )-type oxide of pseudo-cubic perovskite-related structure (space group: $\mathrm{Im}^{3}$ ) with a lattice parameter of $7.391 \AA$. The huge value of $\varepsilon$ remaining constant over a wide range of temperatures from 100 to $400 \mathrm{~K}$ for CCTO allows for its use in wide potential applications [2-4].

The advancement of technology requires a material with giant $\varepsilon$ value to reduce the size of electronic components, whereas the effective performance of these electronic components requires substantially low $\tan \delta$. For this reason, a great number of theoretical and experimental researches have been carried out to reveal the nature and the origin of the giant $\varepsilon$ value of CCTO ceramics. Various processing routes (chemical and physical methods) of CCTO were adopted such as solid-state reaction, wetchemistry route, sol-gel, solution combustion synthesis, sonochemical-assisted route, and co-precipitation [5-10]. The solid-state reaction is a common method for the synthesis of CCTO from $\mathrm{CaCO}_{3}, \mathrm{CuO}$, and $\mathrm{TiO}_{2}$ at high 
temperatures accompanied by drawbacks like heterogeneity of precursor materials and long reaction time [11-14]. A few other drawbacks are secondary phases which appear during the synthesis because of limited atomic diffusion through micrometer-sized grains. It is well known that the electric properties can be remarkably enhanced when ceramic has a homogeneous microstructure. Other methods are available to improve CCTO characteristics, but not without some drawbacks.

The study of CCTO has been attracting interest due to its molecular structure and wide applications. For instance, it has been applied in capacitors, antennas, microwave devices, and sensors. CCTO for sensor applications shows benefit from the point of view of its polycrystalline porous nanostructures. One of the most significant properties of CCTO sensor is to detect and monitor gases and toxic species without decomposition or change in their structural arrangements. Researches have been carried out on CCTO to enhance its sensitivity and selectivity on gas sensing, chemical and bio-sensors. However, little work has been published on some aspects of CCTO's sensing applications, and this still remains as a potential research area. The CCTO gas sensor is considered non-ohmic device because electric properties are greatly dominated by grain-boundary interface states [15]. These non-ohmic ceramic devices are also known as "metal-oxide" varistors (variable resistors) applications of which are technologically important because of their electric characteristics that enable them to be used as solid-state switches with large-energy-handling capabilities. The varistors are also know as voltage-dependent resistors because they show a highly nonlinear currentvoltage $(I-V)$ characteristic. The first voltage-dependent resistors polycrystalline ceramics were developed around early the 1930s by the Bell System and consisted of partially sintered compacts of SiC. A voltage-dependent resistor-based system with very superior performance based on CCTO composition was announced in 2005 by Il-Doo Kim [16] although parallel developments were reported in Brazil in the early part of 2008 [17]. This research revealed a mechanism responsible for remarkable electron transportation (n-type or p-type conductivity) which depends on the synthesis methods and experimental conditions $[18,19]$.

This study reviews the principal methods for the fabrication of CCTO, and the determination of its structure, factor influence on dielectric properties, the immobilization, and sensing applications. Apart from the limited studies by researchers on CCTO electroceramic as a gas sensor, there are no comprehensive reviews on its sensing applications, while even the few available only focus on the dielectric properties of bulk ceramics and dense films.

\section{Synthesis Methods of CCTO}

Different synthesis methods have been adopted by various researchers to obtain CCTO electroceramic in order to tailor its dielectric properties.

\subsection{Solid-State Reaction Method}

CCTO is generally synthesized by a conventional solidstate method or dry route $[20,21]$. The method normally uses stoichiometric amounts of the common precursors, i.e., $\mathrm{CaCO}_{3}, \mathrm{CuO}$, and $\mathrm{TiO}_{2}$ for being mixed with suitable liquid (acetone or ethanol), using ball mill. To remove volatile impurities, the fine powder is calcined at $930{ }^{\circ} \mathrm{C}$ for a designated period of time $(12 \mathrm{~h})$. An appropriate amount $\left(1 \mathrm{cc} \mathrm{mL}^{-1}\right)$ of a suitable binder (PVA) is added to the powder and mixed uniformly before being compressed to form a pellet shape. The resulting product is first heated slowly (at a heating rate $5{ }^{\circ} \mathrm{C} \mathrm{min}^{-1}$ ) to a particular temperature $\left(1040^{\circ} \mathrm{C}\right)$ to burn off the binder. The mixture is then maintained at this temperature for $10 \mathrm{~h}$ for annealing. The sample is later cooled under a controlled rate of cooling (cooling rate $5{ }^{\circ} \mathrm{C} \min ^{-1}$ ). A systematic flow chart of a solid-state reaction method is shown in Fig. 1.

The chemical reaction during the conventional solidstate reaction method for the synthesis of CCTO is shown in Eq. 1:

$\mathrm{CaCO}_{3}+3 \mathrm{CuO}+4 \mathrm{TiO}_{2} \rightarrow \mathrm{CaCu}_{3} \mathrm{Ti}_{4} \mathrm{O}_{12}+\mathrm{CO}_{2} \uparrow$

Shao et al. [22] prepared $\mathrm{CaCu}_{3} \mathrm{Ti}_{4} \mathrm{O}_{12}$ ceramics by the conventional solid-state reaction method under various

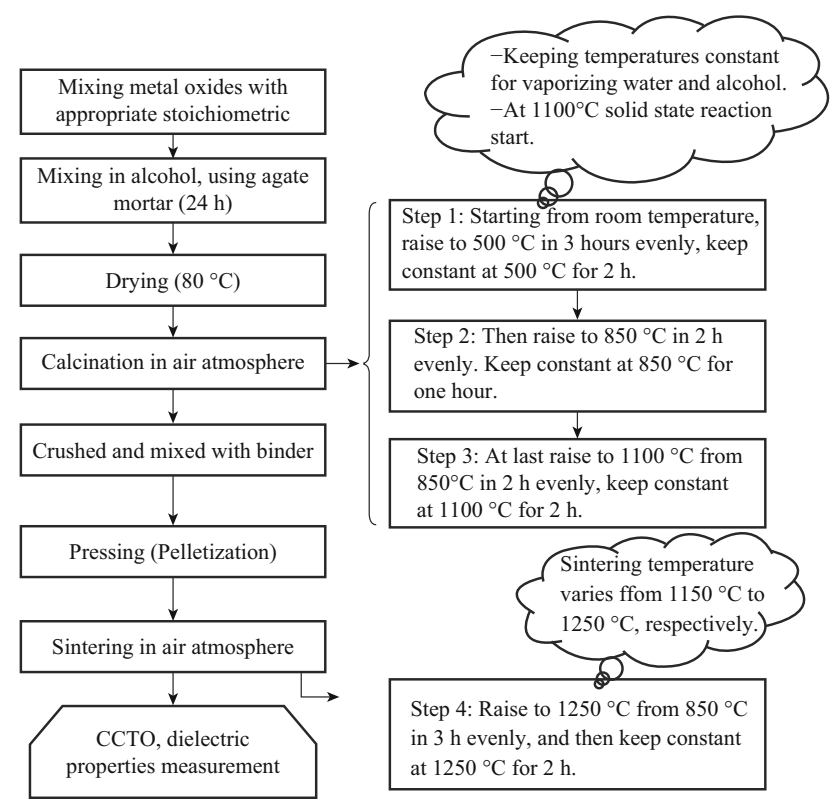

Fig. 1 Flow chart for the synthesis of pure CCTO by solid-state route 
sintering temperatures from 1000 to $1120^{\circ} \mathrm{C}$ at intervals of $10{ }^{\circ} \mathrm{C}$. It was reported that the morphologies changed significantly with the sintering temperature. Ceramic specimens prepared by this method had a good polycrystalline structure in spite of the different microstructures. The $\varepsilon$ value was found to increase with the increasing sintering temperature and have a close relation with the polycrystalline microstructure and particularly the grain size.

However, solid-state route method suffers the disadvantages of inhomogeneity, and the need for repetitive grinding, the need for firing at high temperatures, and a prolonged reaction time.

\subsection{Wet-Chemistry Method}

Wet-chemistry method is a type of combustion synthesis technique that is based on redox reaction between a fuel and an oxidant in a precursor solution. In general, citric acid, urea, ethylene glycol, etc. are used as a fuel, while nitrates of different metals are used as oxidants. The chelating agents like EDTA, acetic acid, etc. can form complex with metal ions in the precursor solution and act as a fuel. This complex in the dehydration process produces a viscous gel which can further undergo self-ignition along with the evolution of huge amount of gases. In the combustion method, the calcium/copper/titanium/citrate aqueous solution becomes a viscous, transparent blue gel after the evaporation of water. After heat treatment, all organic materials burned out, and a voluminous porous black sample is left behind. This leads to the remnant of fine phase pure powder. The systematic flow chart of the wetchemistry method is depicted in Fig. 2.

Liu et al. [23] reported the synthesis of fine CCTO powder using the wet-chemistry method at relatively low temperatures and with a shorter reaction time. The purephase sample was obtained at $800{ }^{\circ} \mathrm{C}$ after sintering for $5 \mathrm{~h}$, and the grain-sized pellet sample was sintered at $1030{ }^{\circ} \mathrm{C}$ for $4 \mathrm{~h}$. The samples had a homogeneous distribution in the range of $0.4-1.5 \mu \mathrm{m}$. This method started with the mixing a homogeneous liquid solution with cation ingredients, in stoichiometric ratio at the atomic scale. Therefore, pure samples at nanoscale could theoretically be obtained at lower temperature and a shorter reaction time than that obtained by solid-state reactions.

\subsection{Sol-Gel Method}

This method is also known as the Pechini, or liquid mix process and widely used in the fields of material science and ceramic engineering. The sol-gel process is also known as chemical solution deposition. In 1967, Maggio P. Pechini developed a sol-gel method for lead and alkaline
Titanium (IV) isopropoxide mixed acetylacetone for

5 min with constant stirring using a magnetic stirrer

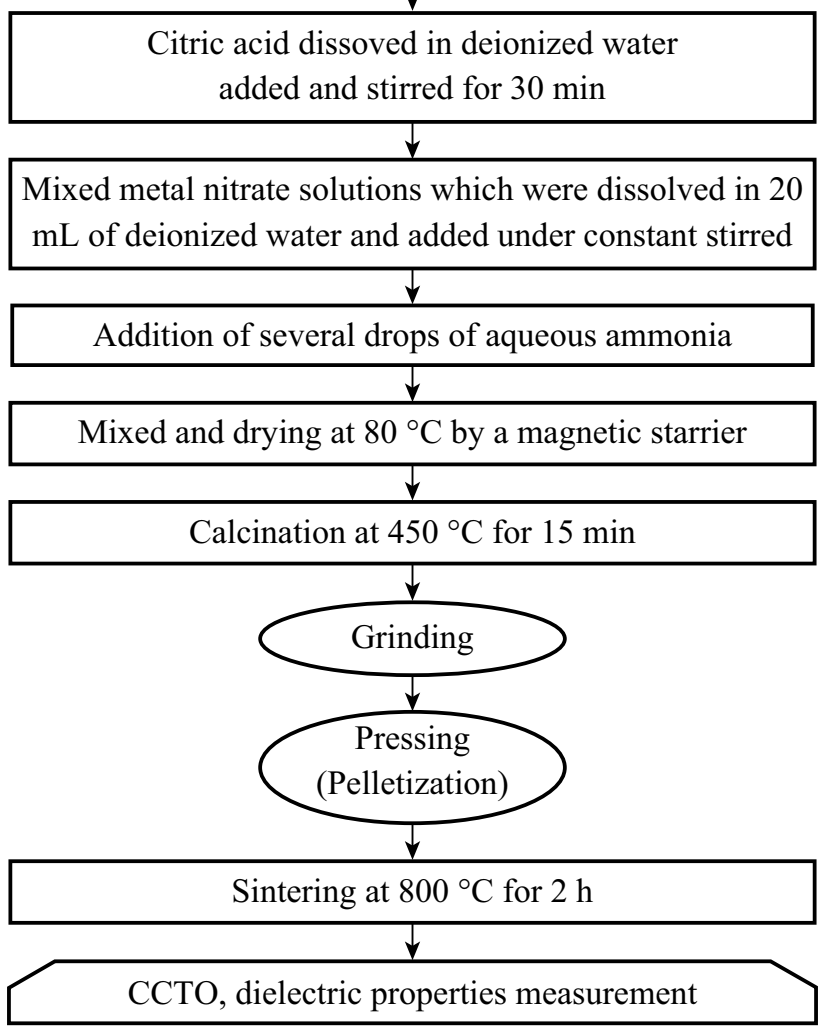

Fig. 2 Flow chart for the synthesis of materials by a wet-chemistry method

earth titanates and niobates, materials that do not have favorable hydrolysis equilibria. Such methods are used primarily for the fabrication of materials (typically a metal oxide) starting from a chemical solution (or sol) that acts as the precursor for an integrated network (or gel) of either discrete particles or network polymers. Typical precursors are metal alkoxides and metal chlorides, which undergo various forms of hydrolysis and poly condensation reactions. Factors that need to be considered in a sol-gel process are solvents, temperature, precursors, catalysts, $\mathrm{pH}$, additives, and mechanical agitation. These factors can influence the kinetics, growth reactions, hydrolysis and condensation reactions. The solvent influences the kinetics and conformation of the precursors, while $\mathrm{pH}$ affects the hydrolysis and condensation reactions. Acidic conditions favor hydrolysis, which means that fully or nearly fully hydrolyzed species are formed before condensation begins. Under acidic conditions, there is a low crosslink density, which yields a denser final product when the gel collapses. These reactions are carried out at room temperature, and further heat treatments need to be conducted for obtaining the final crystalline state. Sol-gel routes can be used to 
prepare pure, stoichiometric, dense, particles of CCTO [24-26]. The flow chart of synthesis of CCTO is shown in Fig. 3.

Liu et al. [27] have synthesized CCTO using the giant $\varepsilon$ material by a sol-gel method using nitrate and alkoxide precursors. The $\varepsilon$ of CCTO was found to be three times smaller than that synthesized by other low-temperature methods including solid-state reaction method. Their results were explained by internal barrier layer capacitor (IBLC) model of Schottky barriers at grain boundaries between semiconducting grains. A sol-gel process showed considerable advantages, including excellent chemical stoichiometry, compositional homogeneity, and lower crystallization temperature due to the mixing of liquid precursors at the molecular level [28, 29] compared with other techniques. Ion-diffusing displacement is shortened in a sol-gel process. The pure phases of the powders were obtained upon calcination at $900{ }^{\circ} \mathrm{C}$ for $1 \mathrm{~h}$. The $\varepsilon$ of CCTO ceramics was found to be 35,000 at $1 \mathrm{kHz}$ in sintered samples at $1060{ }^{\circ} \mathrm{C}$ for $48 \mathrm{~h}$.

\subsection{Combustion Synthesis Technique}

Combustion synthesis in solid-state chemistry is also known as metathesis reaction or self-propagating hightemperature synthesis (SHS). By this method, homogeneous nanopowder, and multi-component single-phase material can be produced. The SHS is one of the effective and economic methods [30] and has emerged as an important technique for the synthesis and the processing of advanced ceramics, catalysts, composites, alloys, intermetallics, and nanomaterials [31]. The method exploits self-sustaining solid flame-combustion reaction for the internal development for a limited short period [32]. The combustion synthesis was first studied by Alexander Merzhavov in 1970s [33] and was reviewed by Gillan and Kaner [34]. A typical reaction occurred between a metal halide and an alkali or alkaline earth main group compounds.

The emphasis in the ceramic synthesis is the need for high reaction temperatures in order to achieve practically usable coefficients of diffusion for the atoms in the reacting solids. Mechanical alloying offers an alternative to high reaction temperatures (i.e., high-pressure pulses), which themselves can be a source for local rapid heating. In the combustion synthesis, high temperatures again take center stage. Consequently, the high temperature is achieved not by placing the sample in a furnace, but by means of the heat generated by exothermic chemical reaction that sustains the high temperature for a duration of around 30-45 s to form the desired end-product of the reaction. Thus, the heating is spontaneous, releasing a large amount of gases during the combustion process with the consequent formation of a nanosized, porous, and foamy product. The

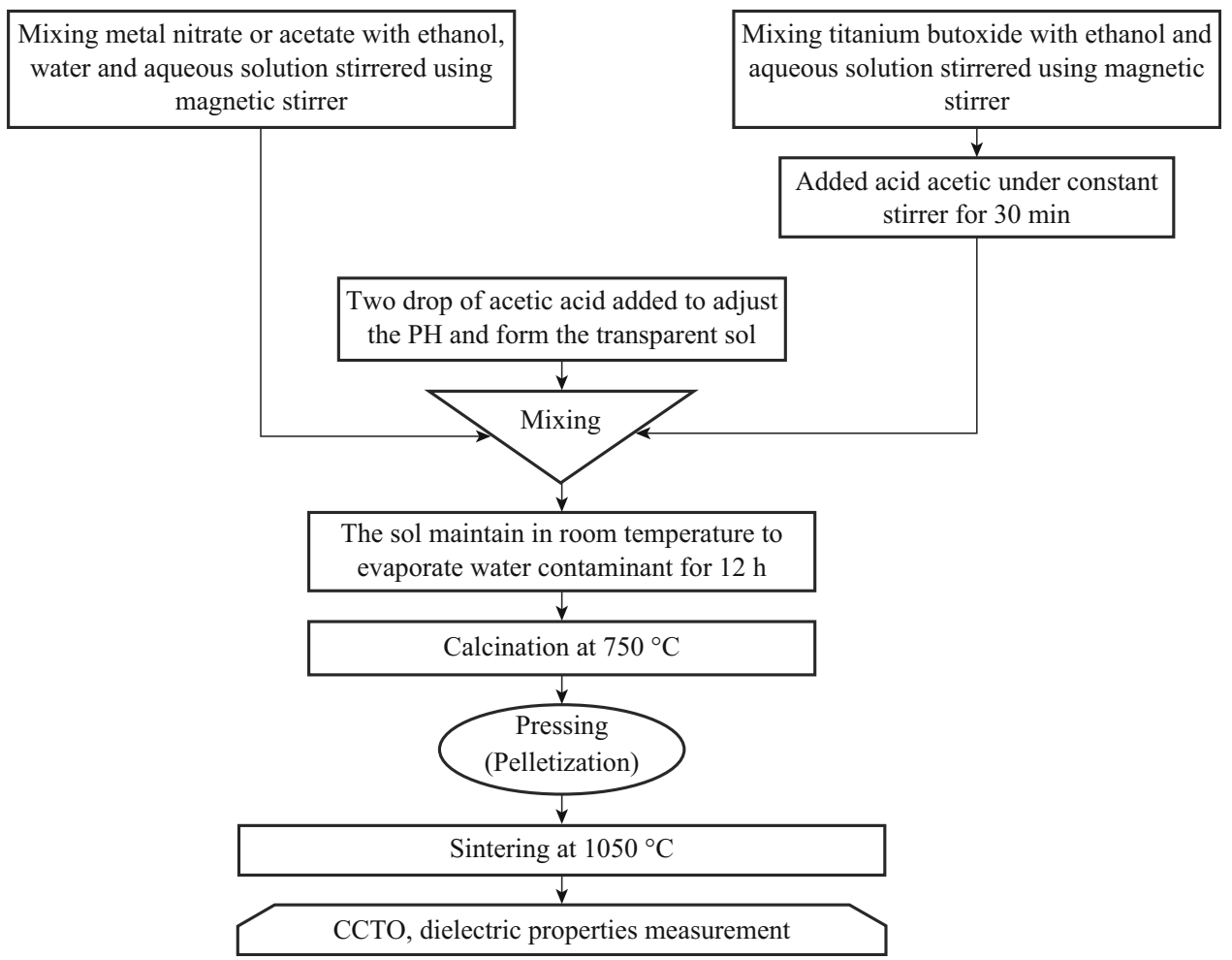

Fig. 3 Flow chart for the synthesis of materials by a sol-gel method 
mechanism of the combustion reaction is quite complex. The parameters that influence the reaction kinetics and mechanisms include the type of fuel, the fuel-to-oxidizer ratio $(\Psi)$, the use of excess amount of oxidizer, the ignition temperature, and water content of the precursor mixture. It is well recognized that the fuel is an important component for the preparation of oxides by combustion synthesis. If the fuel-to-oxidizer ratio is unity, the energy released by the combustion is maximized. Fuel-to-oxidizer ratio is calculated and expressed as shown in Eq. 2:

$\psi=\frac{\text { Oxidizing and reducing elements in fuel }}{\text { All oxidizing and reducing elements in oxidizer }}$

The ratio is crucial and effective in this method [35, 36]. It can change the properties of the nanomaterial as the reaction temperature is dependent on fuel-to-oxidizer ratio. In general, citric acid, urea, or ethylene glycol is used as a fuel, and nitrates of different metals are used as oxidants.

Patra et al. [37] have completely synthesized the nanopowder CCTO by citrate-nitrate gel combustion technique followed by calcination in the temperature range of $700-800{ }^{\circ} \mathrm{C}$. The average crystalline size of synthesized powders was $66 \mathrm{~nm}$, and the particle size ranged between 189 and $300 \mathrm{~nm}$. Sintering of the powders was conducted in air at $1000{ }^{\circ} \mathrm{C}$ for $4-6 \mathrm{~h}$. The X-ray diffraction (XRD) study revealed that CCTO powder calcined in $700{ }^{\circ} \mathrm{C}$ had some extra peaks that were unable to be identified at $800{ }^{\circ} \mathrm{C}$, where XRD showed pure CCTO without any impurity. Scanning electronic microscopy (SEM) images of the sintered CCTO ceramics showed submicron grain size distribution of the sample in $1000{ }^{\circ} \mathrm{C}(4 \mathrm{~h})^{-1}$ and an illustrated matrix consisting of large grains, wherein the small grains were embedded between the large grains at $1000{ }^{\circ} \mathrm{C}(6 \mathrm{~h})^{-1}$. The samples exhibit very high dielectric permittivities of 6800 and 23,200 , and dielectric losses of 0.21 and 0.61 for $1000{ }^{\circ} \mathrm{C}(4 \mathrm{~h})^{-1}$ and $1000{ }^{\circ} \mathrm{C}(6 \mathrm{~h})^{-1}$ at $1 \mathrm{kHz}$, respectively. This method was found very attractive due to its relatively greater effectiveness and economy in operational cost for obtaining a homogeneous and fine powder precursor. Figure 4 shows the combustion reaction flow chart.

\subsection{Sonochemical-Assisted Process}

Sonochemical originates from the extreme transient conditions induced by ultrasound which produces unique hot spots that can withstand temperatures and pressures of, respectively, above even $5000 \mathrm{~K}$ and 1000 atmospheres, with the heating and cooling rates being in excess of $1010 \mathrm{~K} \mathrm{~s}^{-1}$. The speed of sound in a typical liquid is $1000-1500 \mathrm{~m} \mathrm{~s}^{-1}$, and the ultrasonic wavelengths will

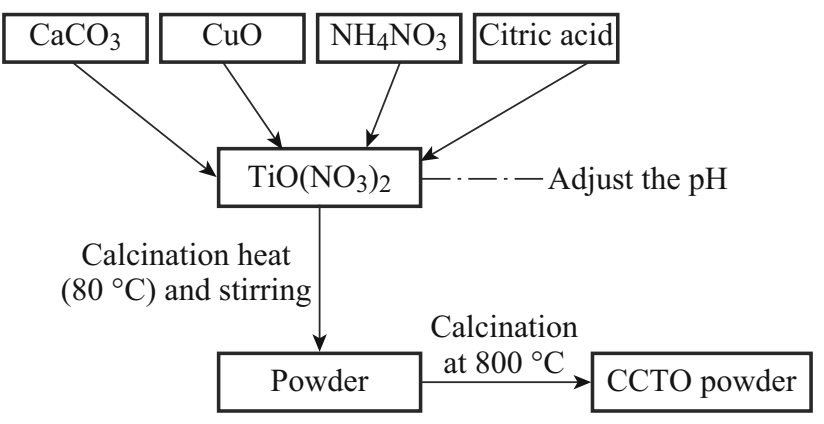

Fig. 4 Flow chart of CCTO powder synthesis by a solution combustion method [37]

vary from roughly $10 \mathrm{~cm}$ down to $100 \mu \mathrm{m}$ over a diminishing frequency range of $20-15 \mathrm{MHz}$, which is much larger than the molecular-size scale. The chemical and physical effects of ultrasound, therefore, arise not from a direct interaction between chemical species and sound waves, rather from the physical phenomenon of acoustic cavitation [38] that involves (a) formation, (b) developing, and (c) the implosive collapse of the microcavities. The acoustic waves crossing the liquids are generating a cavity phenomenon. When sound waves with sufficient amplitude propagate through a liquid, the liquid is under dynamic tensile stress, and the density changes with alternating expansive and compressive waves. Bubbles are generated from pre-existing impurities (e.g., gas-filled crevices in dust motes) and oscillate with the applied sound field. Bubbles can grow through a slow pumping of gas from the bulk liquid into the oscillating bubble (rectified diffusion). Bubbles at a critical size (usually tens of micrometers) can couple strongly in response to the extreme transient conditions produced during acoustic cavitation. This allows for the formation of unique materials and also permits syntheses on the benchtop in a room-temperature liquid which would otherwise require high temperatures, high pressures, or long reaction times. When a liquid is irradiated by highintensity ultrasound, high-energy chemical reactions occur. Sonochemistry was employed in the synthesis of materials from volatile or nonvolatile precursors, but generally involving different mechanisms. Sonochemical activation of a starting material led to a precipitation reaction that improves the homogeneity of the final product.

Wongpisutpaisan et al. [39] synthesized the giant dielectric-constant material CCTO by aonochemical-assisted process containing stoichiometric amounts of the metal nitrate, at a shorter reaction time than that of a conventional solid-state reaction. Synthesis from a solution affords intimate and homogeneous mixing of the metal ions at the atomic scale. Thus, this leads to the reduction of the diffusion path length. However, a short diffusion length reduces reaction time. The diameter of the multiphase 
CCTO powders was $500 \mathrm{~nm}$ as obtained by SEM, and the average crystalline size calculated using the Scherrer's equation from the full-width-at-half-maximum (FWHM) of the strongest diffraction peak (220) was $\sim 75 \mathrm{~nm}$. Wongpisutpaisan et al. [39] observed that as the frequency increased over $1 \mathrm{kHz}$, the $\varepsilon$ rapidly decreased. In addition, the higher $\varepsilon$ values at lower frequency could be related to the possibility of the presence of interfacial polarization. The systematic flow chart is illustrated in Fig. 5.

\subsection{Co-precipitation Method}

Co-precipitation reactions are among the oldest techniques for the synthesis of nanomaterials. The reaction precipitate substances are normally soluble under the reaction conditions. There are three main mechanisms of co-precipitation: inclusion, occlusion, and adsorption mechanisms [40]. An inclusion occurs when the impurity occupies a lattice site in the crystal structure of the carrier. The inclusion of impurities results in a crystallographic defect that occurs when the ionic radius and charges of the impurity are similar to those of the carrier. An adsorbate is an impurity that is weakly bound (adsorbed) to the surface of the precipitate. An occlusion occurs when an adsorbed impurity gets physically trapped inside the crystal as it grows.

Barbier et al. [10] synthesized CCTO powders by a soft chemistry method (co-precipitation method). The sintered pellets showed a high room temperature $\varepsilon_{\mathrm{r}}\left(\sim 1.4 \times 10^{5}\right)$ and relatively small $\tan \delta(\sim 0.16)$ at $1 \mathrm{kHz}$. The study suggested that the high dielectric permittivity observed in the material were not related to an interface but, related to mechanism due to the type of the capacitor (an internal barrier layer capacitor (IBLC)) used. The samples prepared from the powder were found to exhibit a bimodal grain size distribution, with small grains of about $20 \mu \mathrm{m}$ and large grains of size ranging from 50 to $200 \mu \mathrm{m}$. Further, they found that the nature of the electrode contact had no influence on the $\varepsilon_{\mathrm{r}}$ and the amounts of loss of CCTO

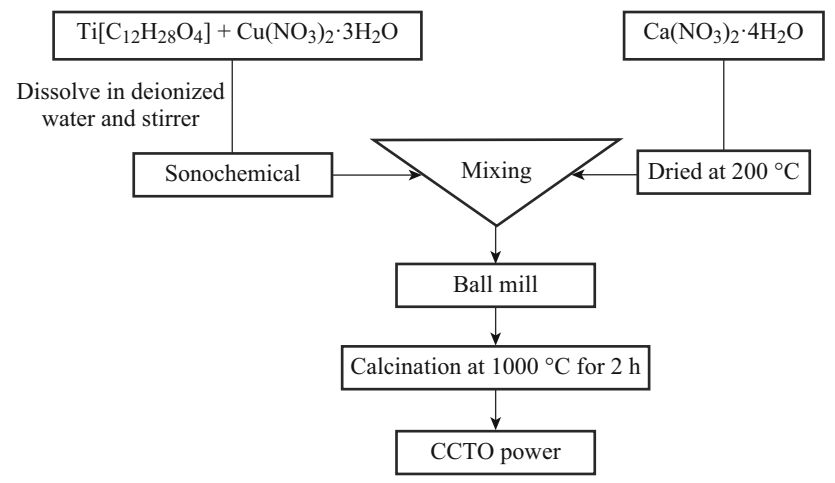

Fig. 5 Flow chart of CCTO powder synthesis by sonochemicalassisted process [39]

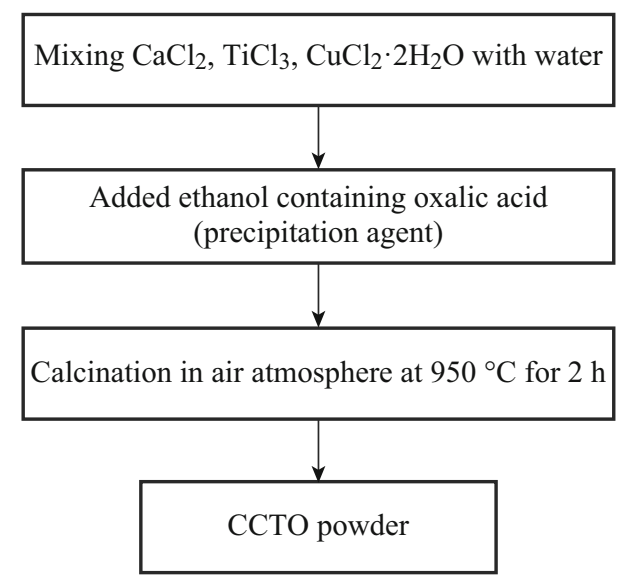

Fig. 6 The flow chart of CCTO powder synthesis procedure by the co-precipitation method

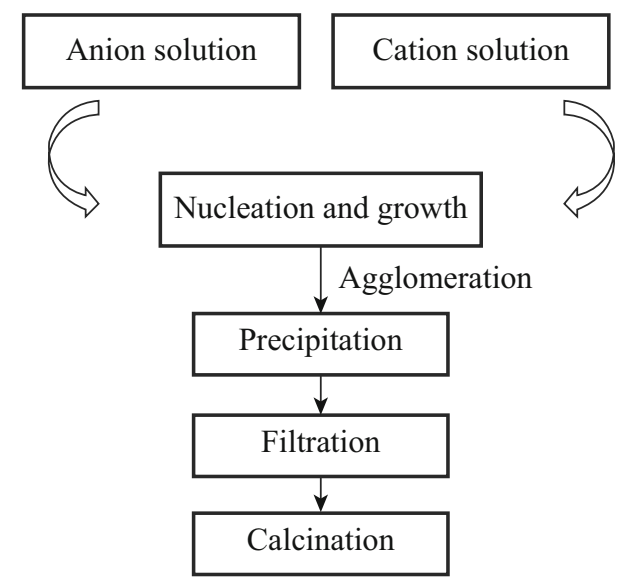

Fig. 7 Preparation of CCTO by the co-precipitation method

pellets. The $\varepsilon_{\mathrm{r}}$ strongly depends on the sample diameter, but, the $\tan \delta$ remains constant regardless of diameter. The systematic flow chart of preparation of CCTO powder by a co-precipitation method is shown in Figs. 6 and 7. Table 1 shows the comparison of CCTO powder-preparation methods in terms of particle size. Similarly, the advantages and disadvantages of the various production methods are explained.

\section{Structure and Dielectric Properties}

The crystal structure of CCTO [41] shown in Fig. 8 can be obtained from the ideal cubic perovskite structure by superimposing a body-centered ordering of $\mathrm{Ca}^{2+}$ and $\mathrm{Cu}^{2+}$ ions share in A-site [42]. The size difference between $\mathrm{Ca}^{2+}$ and $\mathrm{Cu}^{2+}$ causes the $\mathrm{TiO}_{6}$ octahedra to undergo remarkable tilting, leading to a body-centered cubic supercell of space group $\mathrm{Im}^{3}$. Consequently, the $\mathrm{Ti}^{4+}$ ions engrossed centrosymmetric position in the octahedral sites. The tilted 


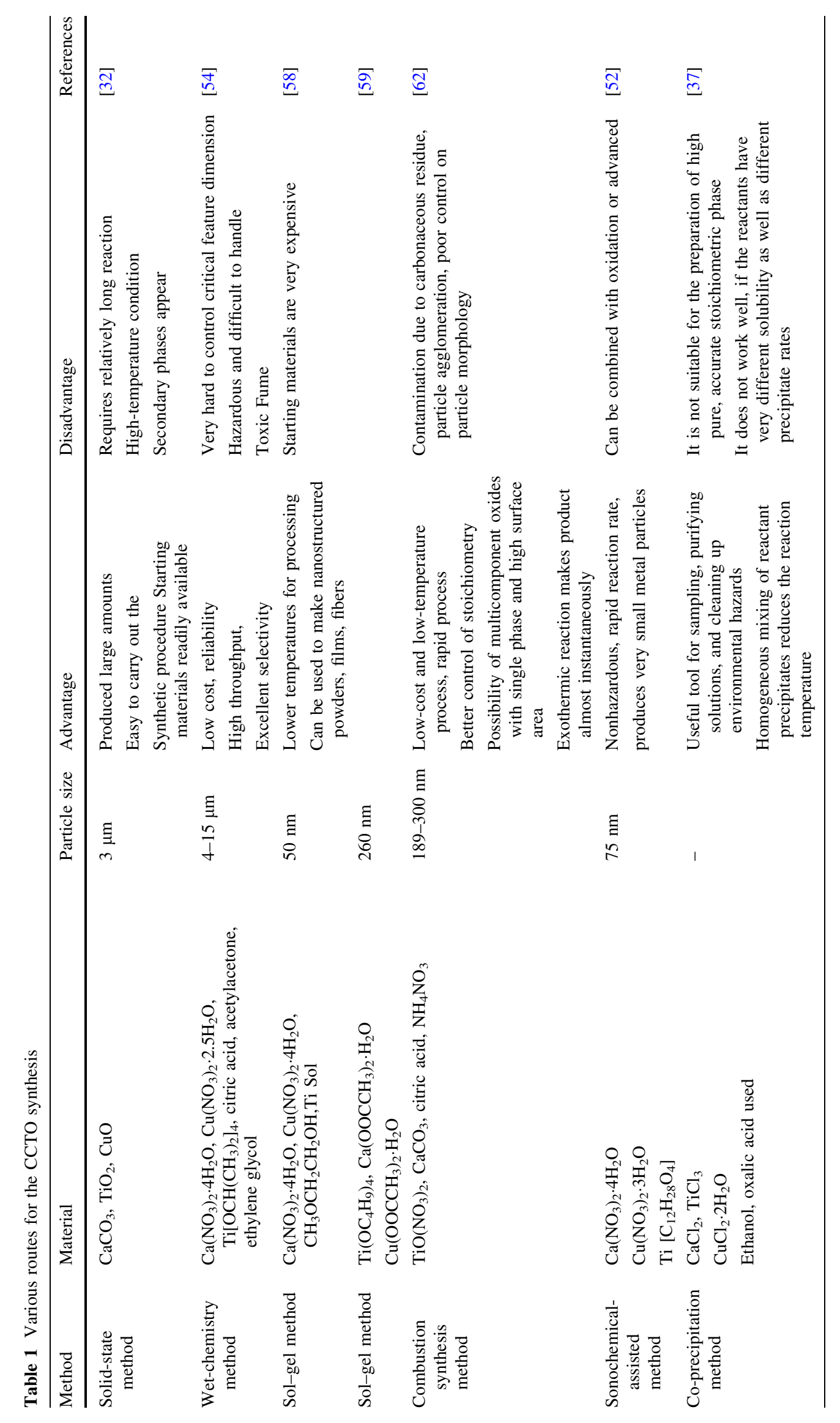




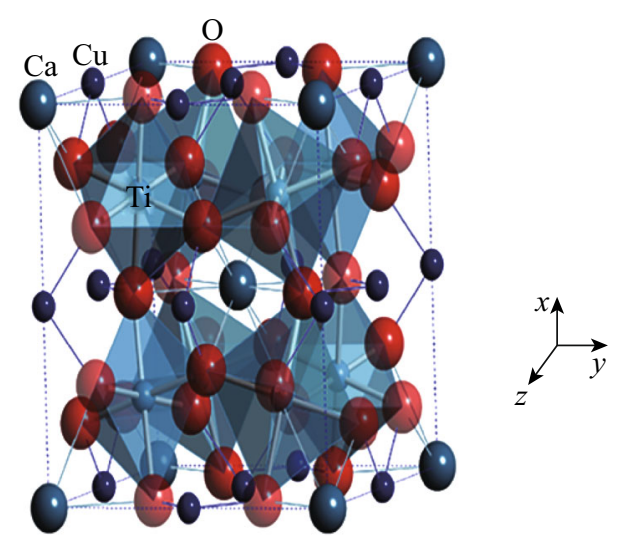

Fig. 8 A crystalline structure of $\mathrm{CaCu}_{3} \mathrm{Ti}_{4} \mathrm{O}_{12}$. Large white blue atoms are $\mathrm{Ca}$, medium-sized dark blue atoms are $\mathrm{Cu}$, red atoms are $\mathrm{O}$, and atoms in the octahedra centers are Ti [43]. (Color figure online)
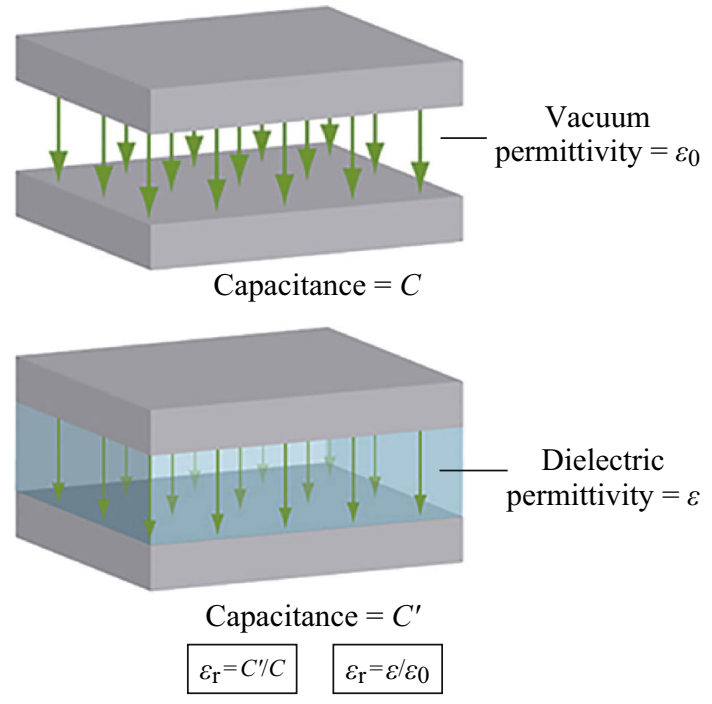

Fig. 9 Dielectric permittivity concept

angle is so appropriate that the $\mathrm{Cu}^{2+}$ ions occupy mostly a square-planer environment [43]. Tilting also significantly changes the coordination environments of the A-site cations which lead to a 4-coordinate square-planar environment for $\mathrm{Cu}$ and a 12-coordinate icosahedral environment for $\mathrm{Ca}$. It is the mismatch in size and the bonding preferences of these two ions and the titanium that drive the large octahedral tilting distortion. The $\mathrm{Ti}^{4+}$ cations could be displaced off center along their one-threefold axis. However, this cannot be a pure ferroelectric transition, because the displacements occur along four different directions. Thus, CCTO has a perovskite-type structure where $\varepsilon_{\mathrm{r}}$ is increased by tension on the Ti-O bonds. Figure 9 illustrates the unit cell of body-centered cubic CCTO with an $\mathrm{Im}^{3}$ space group, which consists of two formula units. The $\mathrm{Ti}$ atoms sit at the center of the canted $\mathrm{TiO}_{6}$ octahedra (the tilt angle is nominally $141^{\circ}$ ), with bridging $\mathrm{Cu}$ atoms bonded to the oxygen atoms, and with large $\mathrm{Ca}$ atoms at the corners and center of the unit cell.

Two main features are needed for any dielectric material in practical applications: high $\varepsilon_{\mathrm{r}}$ and low $\tan \delta$.

\subsection{Dielectric Permittivity}

The $\varepsilon_{\mathrm{r}}$ is the ratio of the capacitance of a capacitor filled with the given material to the capacitance of an identical capacitor in a vacuum without dielectric material. The insertion of a dielectric between the plates of a parallelplate capacitor always increases its capacitance, or ability to store opposite charges on each plate, compared with the ability when the plates are separated by a vacuum. If $C^{\prime}$ is the value of the capacitance of a capacitor filled with a given dielectric and $C$ is the capacitance of an identical capacitor in a vacuum which is showed in Fig. 9. The $\varepsilon_{\mathrm{r}}$ is dimensionless, and simply expressed as $\varepsilon_{\mathrm{r}}=C^{\prime} / C$. It denotes a large-scale property of dielectrics without specifying the electric behavior on the atomic scale.

The $\varepsilon_{\mathrm{r}}$ of CCTO has been reported to range from 100 to 300,000 in pellets, films, single crystals, and polycrystalline microstructures [44-46]. The highest value of $\varepsilon$ remains essentially unchanged ranging from 100 to $400 \mathrm{~K}$. A completely satisfactory explanation is not yet available for this unique and remarkable behavior. However, it is established that the behavior is not related to the ferroelectric transition [47], and the consensus is that the behavior is not intrinsic [48]. According to a well-established barrier layer mechanism for high $\varepsilon_{\mathrm{r}}$, the high $\varepsilon$ values of CCTO have been ascribed as being due to the conducting grains with insulating grain boundaries and its possible source. [49]. However, the exceptionally high $\varepsilon$ values in CCTO crystals dictates that the insulating barriers must be inside the crystals rather than between them. Very high concentrations of twin boundaries seem always to be present in CCTO crystals. It has been suggested that these twin boundaries somehow act as the insulating barriers. An understanding of the dielectric properties of CCTO requires an explanation for the manner in which this titanate develops its conducting regions, and a description of the insulating boundaries within the conducting regions. Although the high $\varepsilon_{\mathrm{r}}$ of CCTO can be rationalized based on its atomic structure, there is a good reason to suspect that the $\varepsilon_{\mathrm{r}}$ of this phase is enhanced by its microstructure. The dielectric behavior is scientifically interesting and technologically intriguing. Therefore, the origin of large dielectric permittivity of CCTO has attracted much attentions. So far, several models though controversial have been proposed to explain the dielectric behavior. The mechanism for the giant dielectric constant of CCTO is still questionable, and investigators are studying it in an effort to understand 
whether the giant dielectric constant is intrinsic to a perfect crystal or extrinsic [50].

\subsection{Dielectric Loss}

Tangent $\delta(\tan \delta)$ or energy loss in a dielectric is due to an alternating electric field, which is a material property rather than geometry property of a capacitor. Usually the $\tan \delta$, expressed as the dissipation factor $\left(D_{\mathrm{f}}\right)$ or loss tangent (tan $\delta$ ) can be mathematically defined as per the Eq. 3:

$\tan \delta=\frac{\varepsilon^{\prime \prime}}{\varepsilon^{\prime}}$

where the angle $\delta$ is supplementary angle of the phase difference between the applied electric field and the induced current. $\varepsilon^{\prime \prime}$ and $\varepsilon^{\prime}$ are the real and the imaginary parts of the $\varepsilon_{\mathrm{r}}$. The value of $\tan \delta$ has been found to be about 0.115 at $1 \mathrm{MHz}$ at room temperature [51]. Therefore, the CСТО, which presents a large $\varepsilon_{\mathrm{r}}$, fails to meet the second requirement. To reduce the dissipation factor $\left(D_{\mathrm{f}}\right)$ by keeping the $\varepsilon_{\mathrm{r}}$ constant, different methods were employed. These include the techniques such as applying different sintering methods or doping additional oxides. In general, dielectric loss of a dielectric material results from distortional, dipolar, interfacial, and conduction loss. The distortional loss is related to electronic and ionic polarization mechanisms. The interfacial loss originates from the excessive polarized interface induced by the fillers, and specifically the movement or rotation of the atoms or molecules in an alternating electric field. The conduction loss is attributed to the $d c$ electric conductivity of the materials which represents the flow of actual charge through the dielectric materials.

\subsection{Factors Affecting the Property and Morphology of CCTO}

Like the influences of doping on CCTO, it seems that different processing conditions can significantly affect the dielectric properties as well. For CCTO, Bender and Pan [52] examined the effects of the processing conditions in detail by using various conditions including the powder mixing, firing temperature (both calcination and sintering), and annealing. They revealed that the $\varepsilon_{\mathrm{r}}$ increased when the CCTO powder was mixed via a milling method accompanied with a higher sintering temperature and a longer sintering time. They also suggested that improvement of $\varepsilon_{\mathrm{r}}$ can be attributed to higher concentration of defects in the grain core.

\subsubsection{Effect of Sintering Temperature and Time}

Sintering of CCTO electroceramic is the method that involves heating the CCTO powder green compact part to a high temperature below the melting point when the material of the separate particles diffuse to the neighboring powder particles. The driving force of sintering process is reduction of surface energy of the particles caused by decrease in their vapor-solid interfaces. The reduction in energy is accomplished by an atomic diffusion process. The process leads to densification of the body by transporting matter from inside the grains into the microstructures of pores of the matter between different parts of the pore surfaces leading to a decrease in the pore volume. Sintering process may be conducted in different atmospheres: inert, and air atmosphere.

Typically, Sinclair et al. [53] reported that the impedance measured at $1 \mathrm{kHz}$ showed great enhancement of $\varepsilon_{\mathrm{r}}$ from $\sim 7700$ of $900{ }^{\circ} \mathrm{C}$ to $\sim 60,000$ of $1050{ }^{\circ} \mathrm{C}$ at $3 \mathrm{~h}$, as illustrated in Table 2. Consequently, the temperature shows a compelling effect on the CCTO grain size, as shown in Fig. 10a, b. It is also obvious that with the increasing grain size, there is corresponding decrease in the total volume faction of boundary layer of the CCTO. Further, the overall permittivity decreases because of the total number of capacitors that are constructed by the microlayers' increases, whereas the total conductivity decreases as some portion of the insulating boundary layer vanishes. Furthermore, time has a characteristic effect on the grain size of CCTO with consequent effect on the $\varepsilon_{\mathrm{r}}$. The grain size reported for the CCTO electroceramic increases from less than $30 \mu \mathrm{m}$ to around $300 \mu \mathrm{m}$ as shown in Fig. 10c, d. The value of $\varepsilon_{\mathrm{r}}$ increases from $\sim 9000$ to $\sim 280,000$ at $3 \mathrm{~h}$ and $24 \mathrm{~h}$, respectively, for CCTO ceramics sintered at $1100{ }^{\circ} \mathrm{C}$, as revealed in Table 3 . The $\varepsilon_{\mathrm{r}}$ obviously increases with the sintering temperature and time as shown in Tables 2 and 3 . It is also accordingly closely related to the polycrystalline microstructure, particularly to the grain sizes.

\subsubsection{Effect of Doping}

A doping method opens an effective way to alter the electric performance, both high $\varepsilon$ and low $\tan \delta$ are

Table 2 Effects of sintering temperatures on dielectric permittivity of CCTO

\begin{tabular}{lrcl}
\hline Time (h) (constant) & $\mathrm{T}\left({ }^{\circ} \mathrm{C}\right)$ & $\varepsilon_{\mathrm{r}}($ at $1 \mathrm{kHz})$ & References \\
\hline 3 & 900 & 7700 & {$[53]$} \\
& 1050 & 60,000 & {$[53]$} \\
5 & 1040 & 5000 & {$[55]$} \\
& 1060 & 84,600 & {$[55]$} \\
10 & 1000 & 1200 & {$[27]$} \\
& 1120 & 60,000 & {$[27]$} \\
12 & 1000 & 1200 & {$[56]$} \\
& 1025 & 5500 & {$[56]$} \\
& 1100 & 100,000 & {$[56]$} \\
\hline
\end{tabular}



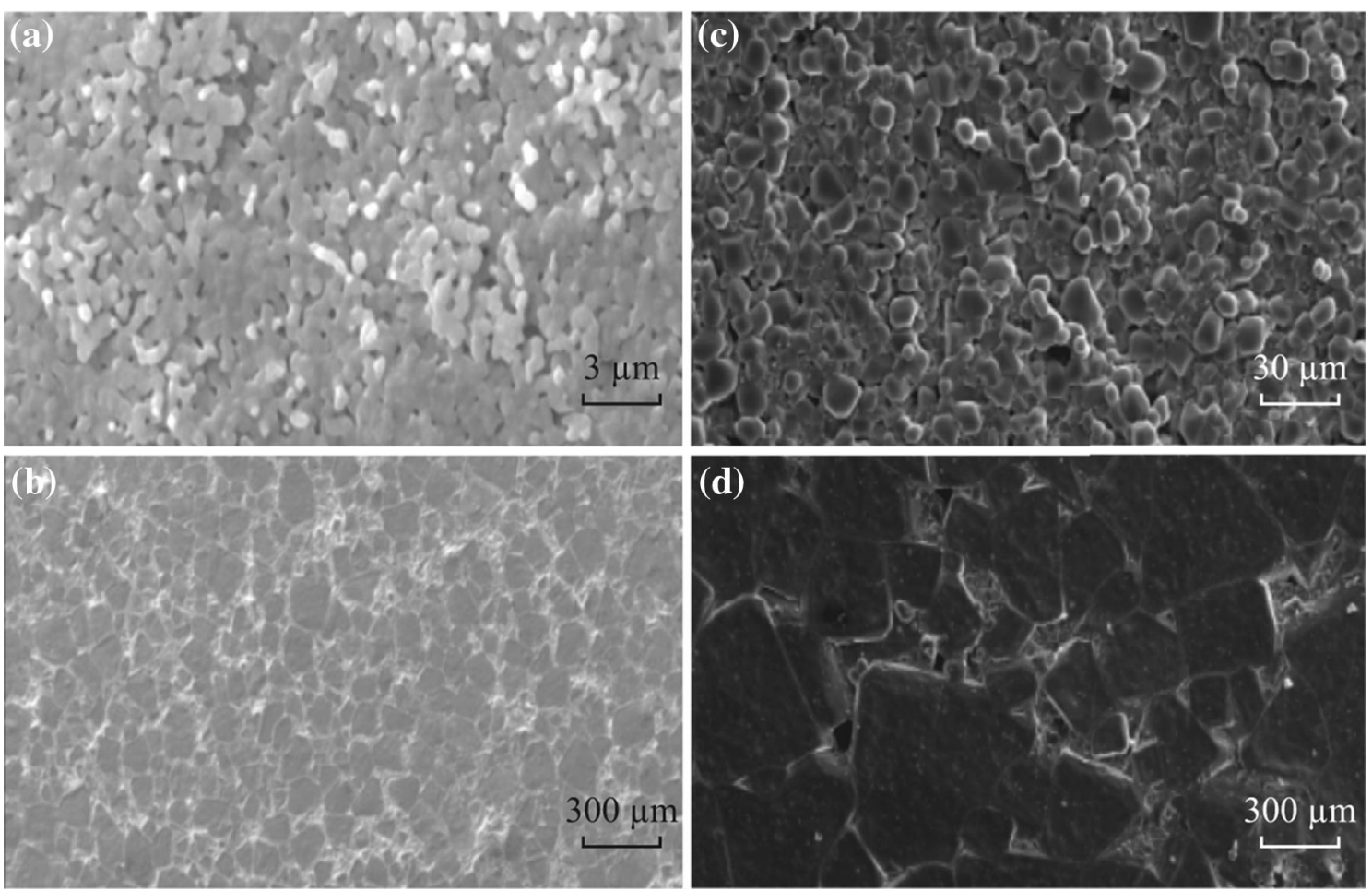

Fig. 10 SEM images of ceramic microstructure for CCTO ceramics sintered for $3 \mathrm{~h}$ for a $900{ }^{\circ} \mathrm{C}$, and $\mathbf{b} 1050{ }^{\circ} \mathrm{C}$. CCTO ceramics sintered at $1100{ }^{\circ} \mathrm{C}$ for $3 \mathrm{~h}(\mathbf{c})$ and $24 \mathrm{~h} \mathrm{(d)}$

Table 3 Effects of sintering times on dielectric permittivity of CCTO

\begin{tabular}{lrrr}
\hline $\mathrm{T}\left({ }^{\circ} \mathrm{C}\right)$ (constant) & Time $(\mathrm{h})$ & $\varepsilon_{\mathrm{r}}($ at $1 \mathrm{kHz})$ & References \\
\hline 1100 & 3 & 9000 & {$[53]$} \\
& 24 & 280,000 & {$[53]$} \\
1100 & 2 & 16,000 & {$[57]$} \\
& 8 & 30,000 & {$[57]$} \\
& 33 & 59,000 & {$[57]$} \\
1000 & 4 & 1000 & {$[58]$} \\
& 6 & 1900 & {$[58]$} \\
& 8 & 3900 & {$[58]$} \\
1050 & 3 & 20,000 & {$[59]$} \\
& 20 & 40,000 & {$[59]$} \\
1120 & 3 & 514 & {$[60]$} \\
& 6 & 12,400 & {$[60]$} \\
\hline
\end{tabular}

essential for different applications. The dielectric material that has a low dielectric loss and low $\varepsilon_{\mathrm{r}}$ is useful in insulators. However, high $\varepsilon_{\mathrm{r}}$ and low $\tan \delta$ are desirable for a capacitor component. $\mathrm{Co}^{2+} / \mathrm{Co}^{3+}$ doping was studied by Chiodelli et al. [61]. The adopted doping dramatically increased the $\varepsilon_{\mathrm{r}}$ value of CCTO as shown in Table 4. Especially in the case of $5 \%$ Co doping, the $\varepsilon_{\mathrm{r}}$ was raised to 147,000 , which is 15 times larger than that of the undoped CCTO.
The reasons for the observed wide variation in dielectric properties for CCTO are unknown: it is because the nature of its giant permittivity is still open to scientific debate.

Hong et al. [64] studied the effects of isovalent dopant $\mathrm{Nb}$ on the dielectric properties of CCTO. The CCTO was doped with different concentrations of $\mathrm{Nb}^{5+}(x=0,0.02$, $0.1,0.2,0.4)$. They found that the dopant concentration has profound effect on the $\varepsilon_{\mathrm{r}}$ of CCTO. The resistivity of boundary layers and $\varepsilon_{\mathrm{r}}$ of the CCTO increase with the increasing dopant concentrations.

XRD was utilized in their work to observe changes in lattice parameters and phase evolution. The XRD data showed a modest linear increase in lattice parameters with the addition of dopant up to $x=0.4$. Therefore, they concluded that the added $\mathrm{Nb}^{5+}$ was most likely present in the microstructure either in the grain boundaries or as a secondary phase. The XRD data also showed that there was no secondary phase as the grain size reduced to $\sim 7 \mu \mathrm{m}$ with $x=0.1 \mathrm{Nb}^{5+}$ substitution.

Vangchangyia et al. [69] synthesized $\mathrm{Ca}_{1-x} \mathrm{Sr}_{x} \mathrm{Cu}_{3} \mathrm{Ti}_{4}$ $\mathrm{O}_{12}(x=0.05,0.1,0.15,0.2)$ ceramics using a simple thermal decomposition method and studied their dielectric properties. It was found that by increasing the $\mathrm{Sr}^{2+}$ concentrations from 5 to 15 at $\%$, there was slight decrease in $\tan \delta(<0.04)$. However, $\varepsilon_{\mathrm{r}}$ was reduced with its value being still higher than $10^{4}$. 
Table 4 Effects of doping on CCTO

\begin{tabular}{|c|c|c|c|c|c|}
\hline Material & Concentration & $\varepsilon_{\mathrm{r}}\left(10^{3} \mathrm{~Hz}\right)$ & $\tan \delta\left(10^{2}-10^{4} \mathrm{~Hz}\right)$ & Grain size & References \\
\hline \multirow[t]{2}{*}{$\mathrm{Al}^{3+}$} & 0.3 & 16,000 & $\sim 0.1$ & $\sim 5 \mu \mathrm{m}$ & {$[62]$} \\
\hline & 0.06 & 70,000 & $<0.06$ & $47 \mu \mathrm{m}$ & {$[63]$} \\
\hline \multirow[t]{2}{*}{$\mathrm{Nb}^{5+}$} & 0.1 & 400,000 & $<0.2$ & $7 \mu \mathrm{m}$ & [64] \\
\hline & 0.2 & 420,000 & $2 \leq x \leq 0.4$ & $7 \mu \mathrm{m}$ & {$[64]$} \\
\hline \multirow[t]{2}{*}{$\mathrm{Sb}^{5+}$} & 0.05 & 24,000 & $1.5 \leq x \leq 0.2$ & $20 \mu \mathrm{m}$ & {$[65]$} \\
\hline & 0.025 & 20,000 & $1 \leq x \leq 0.2$ & $30 \mu \mathrm{m}$ & {$[65]$} \\
\hline \multirow[t]{2}{*}{$\mathrm{Zn}^{2+}$} & 0.2 & $12,500 \leq x \leq 2500$ & $1.27 \leq x \leq 0.1$ & $1 \mu \mathrm{m}$ & {$[66]$} \\
\hline & 0.05 & 15,000 & 0.029 & $\sim 1 \mu \mathrm{m}$ & [67] \\
\hline \multirow[t]{2}{*}{$\mathrm{Pr}^{3+} / \operatorname{Pr}^{4+}$} & 0.2 & 4500 & $0.4 \leq x \leq 0.1$ & $5 \mu \mathrm{m}$ & {$[68]$} \\
\hline & 0.05 & 3500 & $0.15 \leq x \leq 0.1$ & $4 \mu \mathrm{m}$ & {$[68]$} \\
\hline \multirow[t]{2}{*}{$\mathrm{Sr}^{2+}$} & 0.2 & 14,348 & $0.7 \leq x \leq 0.08$ & - & [69] \\
\hline & 0.1 & 14,369 & $0.08 \leq x \leq 0.04$ & - & [69] \\
\hline \multirow[t]{2}{*}{$\mathrm{Fe}^{3+}$} & 0.2 & 100 & $9.6 \leq x \leq 1$ & $\sim 120 \mu \mathrm{m}$ & [70] \\
\hline & 0.03 & 433 & $5 \leq x \leq 1$ & - & [71] \\
\hline \multirow[t]{2}{*}{$\mathrm{Ni}^{2+}$} & 0.02 & 2500 & 0.15 & $4 \mu \mathrm{m}$ & [72] \\
\hline & 0.2 & 10,000 & $\sim 0.6$ & - & [73] \\
\hline \multirow[t]{2}{*}{$\mathrm{Y}^{3+}$} & 0.02 & 2700 & 0.06 & $200 \mathrm{~nm}$ & [74] \\
\hline & 0.1 & 75,000 & $<0.2$ & $93 \mu \mathrm{m}$ & [75] \\
\hline \multirow[t]{2}{*}{$\mathrm{B}^{3+}$} & 0.03 & 50,000 & $<0.1$ & $12 \mu \mathrm{m}$ & [76] \\
\hline & 0.01 & $\sim 50,000$ & $0.16 \leq x \leq 0.09$ & $10 \mu \mathrm{m}$ & [76] \\
\hline \multirow[t]{2}{*}{$\mathrm{Te}^{2+}$} & 0.02 & 20,000 & $0.1 \leq x \leq 0.05$ & $3.23 \mu \mathrm{m}$ & [77] \\
\hline & 0.01 & 25,500 & $0.12 \leq x \leq 0.05$ & $2.51 \mu \mathrm{m}$ & [77] \\
\hline \multirow[t]{2}{*}{$\mathrm{Co}^{2+} / \mathrm{Co}^{3+}$} & 0.4 & 9500 & $1.3 \leq x \leq 0.5$ & $5 \mu \mathrm{m}$ & [78] \\
\hline & 0.2 & 70,000 & $\leq 0.6$ & $\sim 5 \mu \mathrm{m}$ & [78] \\
\hline \multirow[t]{2}{*}{$\mathrm{Zr}^{4+}$} & 0.1 & 33,000 & $1.6 \leq x \leq 0.2$ & $\sim 10 \mu \mathrm{m}$ & [79] \\
\hline & 0.05 & 15,000 & $2.4 \leq x \leq 0.2$ & $5 \mu \mathrm{m}$ & {$[80]$} \\
\hline \multirow[t]{2}{*}{$\mathrm{Ga}^{3+}$} & 0.05 & 38,011 & $\sim 0.1$ & $136 \mu \mathrm{m}$ & [81] \\
\hline & 0.1 & 66,736 & $0.15 \leq x \leq 0.1$ & $199 \mu \mathrm{m}$ & [81] \\
\hline \multirow[t]{2}{*}{$\mathrm{La}^{3+}$} & 0.05 & 8000 & $0.6 \leq x \leq 0.3$ & - & {$[82]$} \\
\hline & 0.2 & 11,000 & $\sim 0.2$ & $2 \mu \mathrm{m}$ & [83] \\
\hline \multirow[t]{2}{*}{$\mathrm{Mg}^{2+}$} & 0.05 & 10,000 & $\sim 0.2$ & $10.5 \mu \mathrm{m}$ & [84] \\
\hline & 0.1 & 5000 & $\sim 0.2$ & $\sim 6 \mu \mathrm{m}$ & [84] \\
\hline \multirow[t]{2}{*}{$\mathrm{Sm}^{3+}$} & 0.005 & 10,000 & $0.5 \leq x \leq 0.03$ & - & [85] \\
\hline & 0.01 & 1200 & $0.1 \leq x \leq 0.05$ & - & [85] \\
\hline \multirow[t]{2}{*}{$\mathrm{Mn}^{3+} / \mathrm{Mn}^{4+}$} & 0.06 & 45 & - & - & [86] \\
\hline & 0.01 & 22,500 & $\sim 0.5$ & - & [87] \\
\hline \multirow[t]{2}{*}{$\mathrm{Sc}^{3+}$} & 0.08 & 80,000 & $1.1 \leq x \leq 0.1$ & $30 \mu \mathrm{m}$ & [88] \\
\hline & 0.2 & 30,000 & $3 \leq x \leq 0.3$ & $10 \mu \mathrm{m}$ & [88] \\
\hline \multirow[t]{2}{*}{$\mathrm{Ba}^{2+}$} & 0.05 & 8000 & $\sim 0.2$ & $5.79 \mu \mathrm{m}$ & [89] \\
\hline & 0.2 & 1500 & $0.27 \leq x \leq 0.23$ & $\sim 1 \mu \mathrm{m}$ & {$[90]$} \\
\hline
\end{tabular}

Jin et al. [83] examined the effect of $\mathrm{La}^{3+}$ on the compositions of $\mathrm{Ca}_{1-x} \mathrm{La}_{2 x / 3} \mathrm{Cu}_{3} \mathrm{Ti}_{4} \mathrm{O}_{12}$. It was found that these ceramics show enhancement in $\varepsilon_{\mathrm{r}}$ value $\left(1700-1,1000\right.$ at $10^{3}$ $\mathrm{Hz})$ and sufficiently low $\tan \delta(<0.2)$. Over the frequency range from $10^{2}$ to $10^{5} \mathrm{~Hz}, \tan \delta$ values at $x=0.05-0.20$ were small, and almost did not vary with frequency. $\mathrm{La}^{3+}$ doping plays important roles in the observed excellent dielectric properties in $\mathrm{Ca}_{1-x} \mathrm{La}_{2 x / 3} \mathrm{Cu}_{3} \mathrm{Ti}_{4} \mathrm{O}_{12}$ ceramics.

\section{Deposition Techniques of CCTO Thin Films}

Many researchers focused on the preparation of CCTO thin films [91-93] due to their unusual dielectric properties and potential applications for microelectronic devices. The relationship between the dielectric properties and microstructures of the deposited thin films was studied in terms of the different substrates via pulsed laser deposition 
(PLD) [92, 94-96] or sputtering [97] to metal organic chemical vapor deposition (MOCVD) [98, 99] or sol-gel [100-102].

\subsection{Pulsed Laser Deposition (PLD)}

The PLD technique is very effective and well suited for developing epitaxial films, and allows for fabrication of multilayers, heterostructures, and super lattices. The technique was first used by Smith and Turner in 1965 for the preparation of semiconductors and dielectric thin films [103]. The first research on CCTO thin films was published in the IEEE proceedings by Cho et al. [92]. Adoption of PLD method caused ceramic thin films to grow on substrates like $\mathrm{LaAlO}_{3}$ (LAO) (100) and $\mathrm{SrRuO}_{3}$. A study about the PLD parameters to obtain optimized properties in epitaxial CCTO films and comparison between these films and polycrystalline thin films was also done. They concluded that the dielectric responses and mechanisms were similar in both cases; i.e., for both cases, the dielectric behavior can be modeled by series combination of two parallel $R-C$ circuits. The gigantic relaxation process in oriented epitaxial thin-film CCTO was proposed to be caused by the mutual interaction of the domain volume resistance and the domain boundary capacitance. Domain boundaries are likely to be at twin boundaries within the oriented epitaxial thin CCTO film.

Fang et al. [94] reported about obtaining results comparable to epitaxial thin films with thin films produced by $\mathrm{PLD}$ on $\mathrm{Pt} / \mathrm{Ti} / \mathrm{SiO}_{2} / \mathrm{Si}$ substrate. The influence of PLD parameters was studied, and the best films were obtained under oxygen pressure of $26.6 \mathrm{~Pa}$ and $720{ }^{\circ} \mathrm{C}$. The values obtained were 2000 for $\varepsilon_{\mathrm{r}}$ at $10 \mathrm{kHz}$ and below 0.5 for the $\tan \delta$. Fang et al. [104] also studied the influence of multilayers $\mathrm{CaTiO}_{3} / \mathrm{CCTO}$ and $\mathrm{CaTiO}_{3} / \mathrm{CCTO} / \mathrm{CaTiO}_{3}$. Samples were produced by PLD with thicknesses of 8-24 nm for $\mathrm{CaTiO}_{3}$ (CTO) and $500 \mathrm{~nm}$ for CCTO. Simple CCTO was made for comparison purpose, and the results showed that loss is largely reduced by the introduction of CTO buffer layers, while $\varepsilon_{\mathrm{r}}$ value also increased. At $10 \mathrm{kHz}$, the $\varepsilon_{\mathrm{r}}$ of CCTO was about 1005 . The $\varepsilon_{\mathrm{r}}$ value for CTO/CCTO/ CTO was about 1507 (w/CTO $16 \mathrm{~nm}$ ). Besides, the $\tan \delta$ of CCTO was 0.17 , while the $\tan \delta$ for the double-buffered was 0.106 . The authors also presented a study about the introduction of a $\mathrm{SiO}_{2}$ layer with different thicknesses between two layers of CCTO [105]. Films were obtained also by PLD technique. They reported the lower value of $\tan \delta$ and the leakage current density of the multilayer thin films with decreased value of $\varepsilon_{\mathrm{r}}$. Two reasons were pointed out to explain this behavior: one was the improvement in the crystallinity, and the other was the reduction of the free carriers in the multilayered films. Multilayer films with $20-\mathrm{nm} \mathrm{SiO}_{2}$ layer showed a $\tan \delta$ of 0.065 at $100 \mathrm{kHz}$ and a value of $\varepsilon_{\mathrm{r}}$ of approximately 150 . The main drawbacks of PLD are an inhomogeneous energy distribution in the laser beam profile, which consequently gives rise to an inhomogeneous energy profile and angular energy distribution in the laser plume. Due to the involvement of the high laser energies, macroscopic and microscopic particles from the target can be ejected. This effect is detrimental to the desired properties of films and multilayers [94].

Deng et al. [96] investigated experimentally the relationship between the electric properties and the oxidation states of $\mathrm{Cu}$ and $\mathrm{Ti}$ in CCTO thin films deposited by pulsed laser deposition (PLD) on top of 150-nm-thick $\mathrm{SrRuO}_{3}$ conductive layer on top of a $\mathrm{LaAlO}_{3}$ single crystal. Their results demonstrated that the as-deposited CCTO film was made of insulating grain boundaries with semiconducting grains, indicating that the high dielectric-constant can be attributed to barrier layer capacitor (BLC) effects. The capacitance of the grains and grain boundaries can be tuned by changing the annealing atmosphere and temperature. Under an oxygen-absent annealing atmosphere, the electric resistances of the grain boundaries changed greatly, but the resistance of the grains showed almost no change, while under an oxygen-annealing atmosphere, the reverse process occurred. On the basis of this result, it is demonstrated that the origin of the dielectric response of the grains in CCTO films is attributed to their oxygen-loss, while the grain boundaries are close to oxygen-stoichiometry. The high apparent $\varepsilon_{\mathrm{r}}$ value in the CCTO thin film can be suppressed by annealing the sample in air.

\subsection{RF Sputtering}

Prakash et al. [97] reported high-quality films with preferential (220) orientation obtained at a substrate temperature of $650{ }^{\circ} \mathrm{C}$ under a total pressure of $4.86 \mathrm{~Pa}$ with $1 \%$ $\mathrm{O}_{2}$. The $\varepsilon_{\mathrm{r}}$ was reported to be $\sim 5000$ at $1 \mathrm{kHz}$ and $400 \mathrm{~K}$. Also, the frequency of the dielectric relaxation in thin films was found to be much lower than that observed in bulk ceramics, and the dielectric relaxation was much higher.

\subsection{Metal Organic Vapor Deposition (MOCVD)}

Nigro et al. [98] analyzed microstructural thin films of CCTO prepared by MOCVD on $\mathrm{LaAlO}_{3}$ substrates. Unlike other referenced works in this review, they did not report the dielectric response of the CCTO. However, they asserted that the deposited MOCVD films consisted of $\mathrm{CuO}$ grains embedded in a quite amorphous matrix of $\mathrm{Ca}-\mathrm{Ti}$ oxides. After the in-situ annealing step at $900{ }^{\circ} \mathrm{C}$, CCTO phase was formed, and the XRD patterns showed the formation of (100)-oriented CCTO films. In the case of $\mathrm{LaAlO}_{3}$ (100) CCTO films, it was found that $1100{ }^{\circ} \mathrm{C}$ treatment for $24 \mathrm{~h}$ resulted in a very rough and porous 
surface. In contrast, the same annealing treatment carried out on amorphous CCTO samples revealed the formation of large, rounded grains (600-1000 nm) that were homogenously distributed on the surface. However, after rapid thermal annealing processes at $1100{ }^{\circ} \mathrm{C}$, substantial and flat grains (about $5 \mu \mathrm{m}$ ) were observed, which were similar to those of CCTO ceramics with very high $\varepsilon_{\mathrm{r}}$ values. Evidences of the formation of CCTO and $\mathrm{CaTiO}_{3}$ phases were also reported for the films. The group reported in another paper [100] the influences of low $\varepsilon_{\mathrm{r}}$ (low- $k$ ) layers of $\mathrm{SiO}_{2}$ and $\mathrm{Si}_{3} \mathrm{~N}_{4}$ on CCTO morphological properties without conducting dielectric characterization. $\mathrm{SiO}_{2}$ showed better crystallinity than $\mathrm{Si}_{3} \mathrm{~N}_{4}$ due to oxide nature of the buffer layer.

Fiorenza et al. [106] also presented an overview from the process of growing thin films of CCTO to the assessment of the permittivity. Hot-wall MOCVD technique was used to obtain thin films on $\mathrm{LaAlO}_{3}$ (001) substrates. The microscopic property was investigated using atomic force microscope (AFM) equipped with the scanning capacitance microscopy module used in scanning impedance configuration. The investigation demonstrated the presence of a surface-depleted layer at the electrode/CCTO film interface, and simultaneously a huge $\varepsilon_{\mathrm{r}}$ value of 8000 was measured as an extrinsic local behavior. The absence of the barrier at the macroscopic scale for the films thermal treated at $900{ }^{\circ} \mathrm{C}$ was explained by the presence of conducting leaking regions on the films. However, the presence of Schottky barrier was observed for the larger grains of the sample heat treated at $1000{ }^{\circ} \mathrm{C}$ with the rising of a local colossal permittivity.

\subsection{Sol-Gel}

A sol-gel is another method which yields thin film layers. Compared to other methods, sol-gel methods offer several advantages such as (i) good physical and mechanical strength, (ii) low swelling capacity of the material in aqueous or organic solvents, (iii) high chemical inertness, (iv) lower temperatures for processing, and (v) high thermal and photochemical stability. Furthermore, sol-gelbased films require low immobilization temperatures which result in the preservation of the properties of the CCTO thin film. Although the sol-gel process is known for over 150 years, interest in the process began only in the $1980 \mathrm{~s}$ after some studies showed the possibility of incorporating organic molecules and active proteins in porous ceramic matrices.

Jiménez et al. [107] achieved appreciable electric properties in CCTO films obtained by sol-gel method using a non-methoxyethanol route. Solution was produced using a titanium diol-based precursor, obtained by refluxing of $\mathrm{Ti}$ (IV) with 1,3-propanediol in the ratio of $1: 1$ with two solutions of copper acetate and calcium acetate in 2-ethylhexanoic acid in the ratio of 1:10. The group reported $\tan \delta$ with maximum values in the range of $0.2-0.5$, and $\varepsilon_{\mathrm{r}}$ values in the range of 200-400 at room temperature, which depended on the frequency for spin-coated films heat treated at $650{ }^{\circ} \mathrm{C}$. Moreover, Shen et al. [108] studied the switching resistance characteristics dependence on the annealing parameters of thin CCTO films obtained by a sol-gel on silicon-based substrates. Solution without methoxyethanol was composed of calcium and cupric acetates, acetic acid, titanium isopropoxide, ethylenglycol, and formamide. The CCTO films showed resistance switching phenomena when annealed at $700{ }^{\circ} \mathrm{C}$ and above. With the increasing annealing temperature, the crystallinity of the films improved. No report on the dielectric properties of these films was published.

Consequently, reliable results were reported for CCTO films prepared by physical deposition methods as sputtering and PLD. For these techniques, $\varepsilon_{\mathrm{r}}$ was measured to be 6000 for epitaxial films, 2000 for polycrystalline ones with PLD, and 5000 for polycrystalline sputtered thin films. The $\tan \delta$ values reported for these techniques were in the range of $0.5-0.2$ for PLD, whereas no values were found for sputtered films. Compared to chemical solution deposition methods, these results are very good, but those techniques used are very expensive and complex with time-consuming procedures. In addition, it is difficult to control the stoichiometry of the films. Within the chemical solution deposition methods, the sol-gel [109, 110] and MOCVD have been the most preferred methods used to prepare CCTO thin films.

\section{Application of CCTO Thin Films as Sensors}

Semiconducting metal-oxide (SMO) sensors are among the most widely studied groups of chemiresistive gas sensors. These sensors are designed to react with one class of gases whereby the SMO undergoes reduction and oxidation. This process causes the SMO sensors to exchange electrons with the target gas at a certain characteristic rate, thereby affecting the sensor's resistance and yielding a certain signal. The reaction of SMO materials with gases and the result of the conductometric changes were introduced in the early 1950s by Brattein et al. [111]. The direct applications of the SMO sensors as catalysts and electric conductive detectors toward various gases were then introduced by Seiyama et al. [112].

During the past few decades, SMO gas sensors have become a prime technology in many industrial gas-sensing systems. Gas sensor technologies are still evolving and yet to reach their full potential in terms of capabilities and usage. Gas sensors based on metal-oxide thin films, such as 


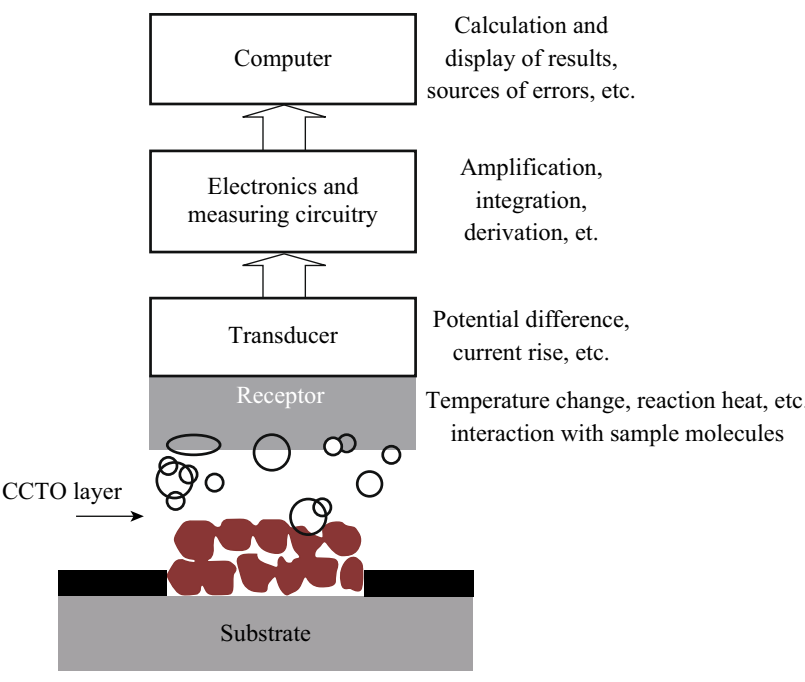

Fig. 11 Schematic representation regarding how an appropriate CCTO-based electrochemical sensor works

$\mathrm{MgO}, \mathrm{Cr}_{2} \mathrm{O}_{3}, \mathrm{NiO}, \mathrm{SrO}, \mathrm{In}_{2} \mathrm{O}_{3}, \mathrm{GeO}_{2}, \mathrm{Nb}_{2} \mathrm{O}_{5}, \mathrm{Ta}_{2} \mathrm{O}_{5}$, and $\mathrm{La}_{2} \mathrm{O}_{3}$, [113], are commonly used in the monitoring of humidity. Gases are based on electrochemical behavior, catalytic combustion, or resistance modulation of SMO [114-120] and can provide the necessary sensitivity and stability required by such system. However, it has difficulties in the measurement of electric conductivity because those materials have large band gaps thereby causing easy formation of electrons and holes. For this reason, CCTO pioneered by Subramanian et al. [1] is being used to improve the sensor properties.

A CCTO-based sensor-that only few researchers' have worked on-can be defined as an analytic device, which consists of an immobilized layer of CCTO on a solid support. If the structures and properties of the СCTO are

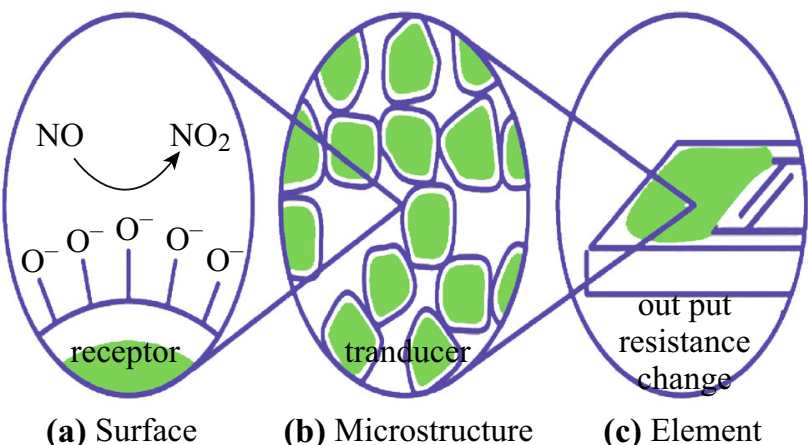

Fig. 12 a Chemisorption and reaction between reducing gases and oxygen adions $\left(\mathrm{O}^{-}\right)$at the surface give rise to the receptor function. b Electronic charge transport through the grains and across grain boundaries gives rise to the transducer function. The latter depends on the microstructure of the sensing layer, e.g., on the grain size and pore size. c The sensor element comprises the sensing layer, electrodes for electric measurements, substrate, and integrated microheater [125] preserved after immobilization, it will recognize the analyte. The chemical reaction between the immobilized CCTO and analyte will then be transformed into an electric signal, which will be amplified and converted by signalprocessing equipment, into a display (Fig. 11). Chemical sensors should transform chemical quantities into electric signals. Chemical sensor should respond exclusively to one analytic, or at least be selective to a group of analyses.

\subsection{Sensing Mechanism}

Considering the influential factors on gas-sensing properties of metal oxides, it is necessary to know the sensing mechanism of a metal-oxide gas sensor. The exact fundamental mechanisms that cause a gas response are still adaptable, but the main responsible reason for conductivity is the trapping of electrons at adsorbed molecules by charged molecules.

Figure 12 illustrates the surface chemical reaction mechanism of CCTO gas sensor upon exposure to reference gas with gas analytes and the microstructure of the sensor on the electric response to the gas [121]. The surface chemical reaction can be referred to as the receptor function of the sensor, because it converts a chemical reaction with the gas analyte into a charge transfer event. This motivates an electric signal, which is amplified by the charge transport mechanism through the sensor or the socalled transducer function of the sensor [122-124].

The important factor that influences the performance of CCTO as a gas sensor is the environmental humidity. However, mechanisms of sensing water vapor and other pollution gases are different. For CCTO, humidity-gas

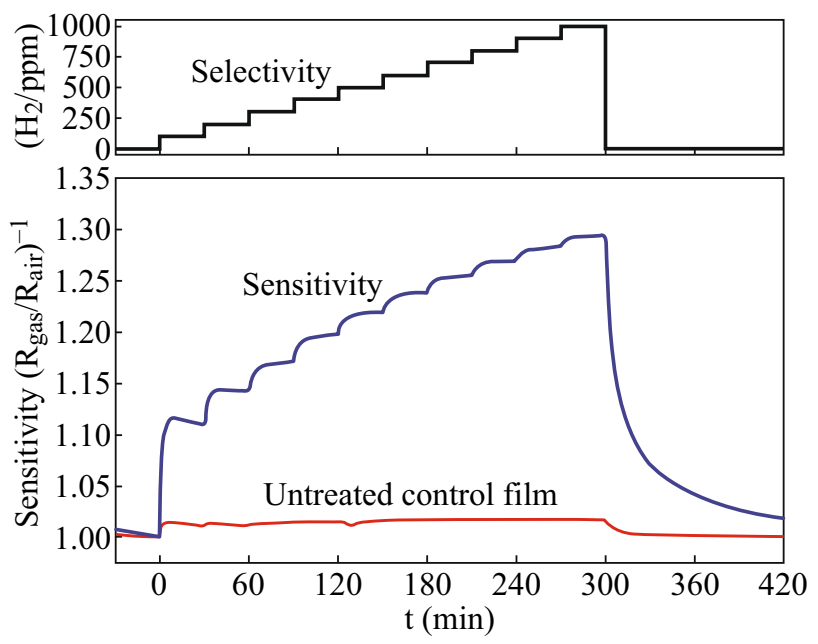

Fig. 13 Main characteristics of CCTO-based sensor constructed and deposited on $\mathrm{Al}_{2} \mathrm{O}_{3}$ substrates with interdigitated $\mathrm{Pt}$ electrode and Amperometric response showing the sensitivity and selectivity of the sensor to successive injections of hydrogen [16] 


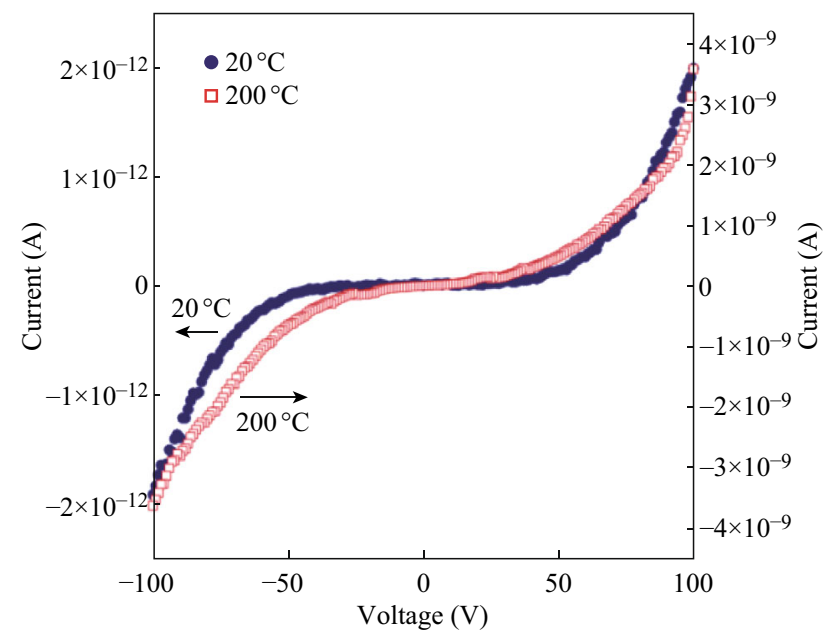

Fig. $14 I-V$ characteristics for CCTO-based sensor at temperature 20 and $200{ }^{\circ} \mathrm{C}$ [16]

sensors and ionic-type humidity sensors are the most commonly used patterns. The conduction mechanism depends on $\mathrm{H}^{+}$or $\mathrm{H}_{3} \mathrm{O}^{+}$, from dissociation of adsorption water [126]. The reaction between the surface oxygen and the water molecules conduces to a decrease in baseline resistance of the gas sensor, and results in a decrease of the sensitivity [127]. Second, the adsorption of water molecules leads to less chemisorption of oxygen species on the

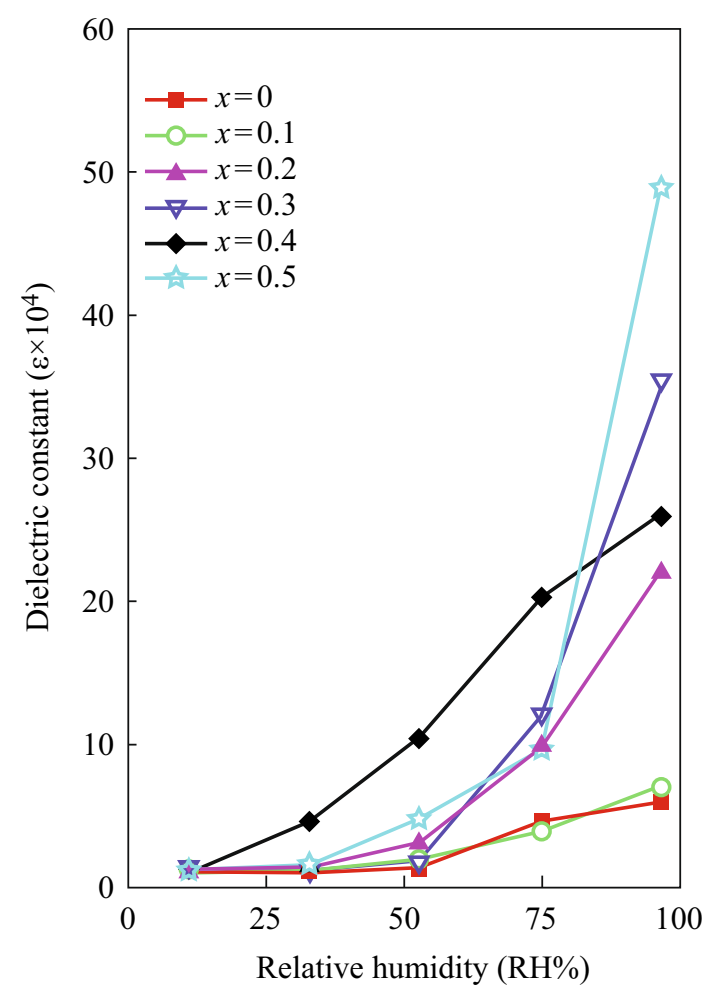

Fig. 15 The humidity sensing characteristics of $\mathrm{CaCu}_{3-x} \mathrm{MgxTi}_{4} \mathrm{O}_{12}$ $(x=0,0.1,0.2,0.3,0.4$, and 0.5$)$ [127]

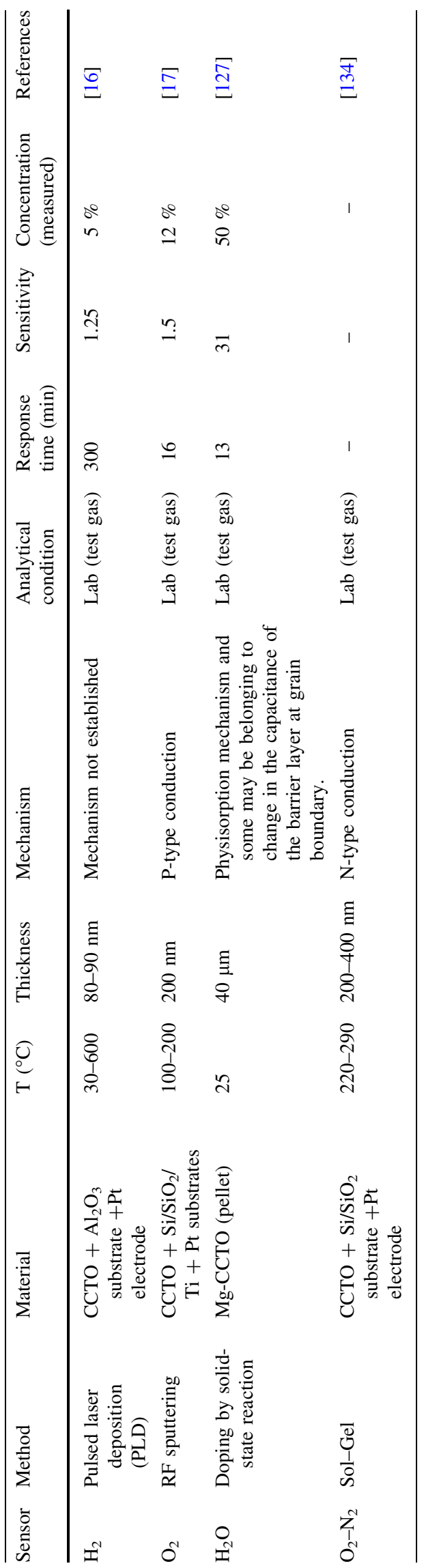




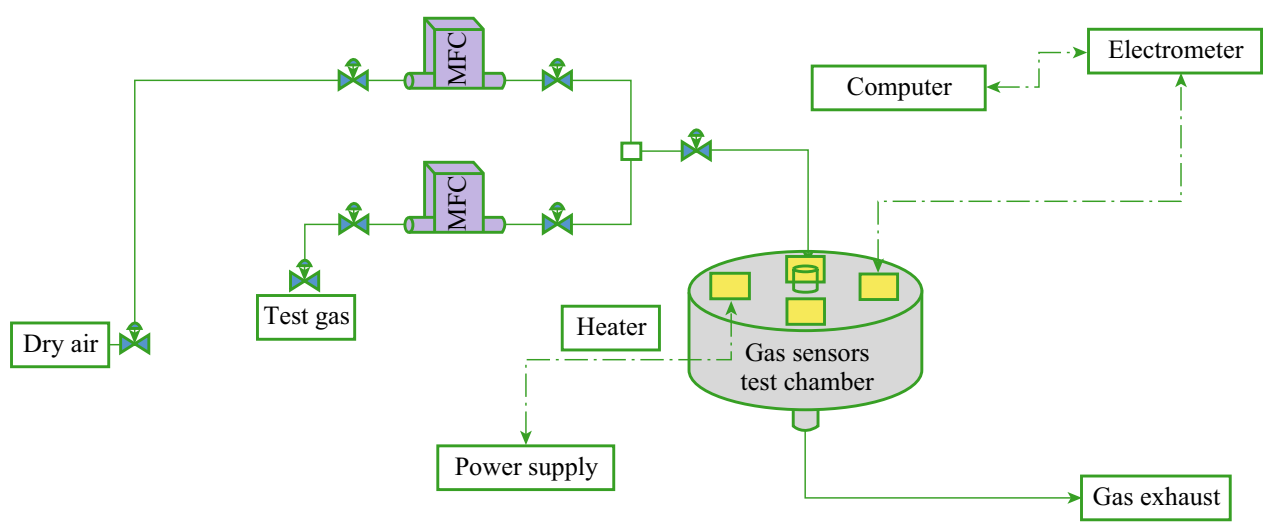

Fig. 16 A general schematic for CCTO gas sensor devices

sensing layer due to the decrease of the surface area that is responsible for the sensor response. Thus, the sensitivity decreases, and the response and recovery times increase.

\subsection{Sensor Properties}

Two important factors in sensor properties are sensitivity and selectivity [128-132]. In general, sensitivity depends on the sensor size, activity of the deposited CCTO toward the specific analyte, success in CCTO immobilization by retaining as much activity as possible [16], and also dopant [116]. Figure 13 illustrates examples of these characteristics for a $\mathrm{Al}_{2} \mathrm{O}_{3}$ substrate coated with CCTO. The selectivity deals with the study of interferences that result mostly from the presence of electroactive species in the test medium. A CCTO-based sensor will be selective if the response to the substrate is high and the response to interferences is low. However, the selectivity of sensors for a given gas in a mixture of two or more reactive gases is debatable.

On the other hand, the nonlinear response of a sensor should result from the slow rate of oxidation or reduction of the CCTO in the presence of the analyte. Highly nonlinear $I-V$ characteristics with strong thermal activation were observed, as shown in Fig. 14. Similar nonlinear behavior has been reported recently for polycrystalline CCTO ceramics by Chung et al. [133].

Li et al. [127] investigated the effect of addition of $\mathrm{Mg}$ to CCTO ceramic-type humidity sensors, which resulted in improved sensitivity and durability as well as in decreased hysteresis. However, sensitivity of doping enhanced CCTO can be seen in Fig. 15.

Gas-sensing properties have also been reported by few researchers for CCTO thin films; the mechanism of a sensor signal is based on conductivity of the CCTO thin film but the type of conductivity in thin films are not well defined in the literature. Kim et al. [16] reported the preparation of macroporous CCTO thin films by PLD onto PMMA (polymethyl methacrylate) microsphere-templated substrates. These films have n-type conductivity and higher $\mathrm{H}_{2}$ sensitivity compared to $\mathrm{CO}$ and $\mathrm{CH}_{4}$. N-type conductivity was also reported by Parra et al. [134], in mesoporous thin films prepared by the sol-gel method. However, Joanni et al. [17] showed that films prepared by rf-sputtering display p-type conductivity. Depending on the synthesized method and experimental conditions, n- or p-type conductivity can be attained. Some of the representative developments in this area are summarized in Table 5.

Also researchers have reported that CCTO-modified electrodes can catalyze and recognize specific analyte species. In order to do this, CCTO-modified electrodes have to exhibit certain characteristics of sensors including response time, sensitivity, and concentration, which are shown in Table 5. An overview of the literature in this field revealed that most modified electrodes satisfy the criteria of molecular recognition between the immobilized CCTO and the specific analyte species in terms of sensitivity and linear range, in some cases.

Although all described sensors comply with the concept of molecular recognition between the CCTO and the specific analyte, unfortunately, not all of them can be considered as appropriate sensors because most of them lack high selectivity and low response time. These are the most important characteristics that a good sensor should possess and display. Given the great potential of CCTO in sensing, further research and development of these processes will enable better understanding of the mechanisms of the sensing pathways.

\subsection{Sensor Testing Setup}

Figure 16 shows the sensor array which mainly consists of a target gas, a multi-component gas mixer, a mass flow controller unit, a testing chamber, a power supplier and heaters, and an electrometer for resistance measurement [121, 135-138]. LabVIEW-based software is mainly used to control all testing parameters and measurements during 
the experiment. The testing chamber consists of CCTObased sensor platforms with the ability to control and measure each sensor's temperature and resistance. The CCTO films are deposited on the sensing element as thin or thick film substrates. Thin film deposits are made via RF sputtering, LPD, and sol-gel techniques. The sensor platform is bonded into a standard header and then placed in a test chamber and temperature adjusted before gas exposure into the chamber.

\section{Conclusions}

The urgent demand for huge $\varepsilon_{\mathrm{r}}$ value ceramics has been a key issue leading to the development of many application technologies. In view of this, scientists and technologists have shown the potential of CCTO with high $\varepsilon_{\mathrm{r}}$ and low tan $\delta$ values for such applications. The critical success of new CCTO materials lies in their methods of preparation which controls the morphology, particle size, and its dielectric properties. In order to obtain these features, small particle size, narrow size distribution, uniform morphology, optimum crystallinity degree, high specific surface area, minimum defects, agglomeration, and homogeneous metal doping are required for the practical applications of CCTO powders. The only limitation which restricts the wide range of applications of this compound is the $\tan \delta$. Methods described in this overview were designed to obtain CCTOs in the form of nano and microcrystalline powders with desired structures and high $\varepsilon_{\mathrm{r}}$ values. Since the number of surface atoms or ions constitutes a significant fraction of their total number, and the surface energy plays an important role in the crystal structure, the materials in the nanometer size range exhibit some remarkable properties which can be exploited to get CCTO with a high $\varepsilon_{\mathrm{r}}$ and low $\tan \delta$. Besides, the gas-sensing process is strongly related to the surface reactions. Hence, high surface areas can provide large reaction contact area between gas-sensing materials and targeted gases. Porous structure with high surface areas seems to be the standard structure of CCTO gas sensor layers. Fabrication of microstructure-based CCTO for novel generation of future advanced CCTObased sensors with appropriate properties in terms of sensitivity, detection limit, response time, and stability are required. Adaptability should also be considered because the final goal of all these sensors is the discovery of analytes in real-life analytic, environmental, and biomedical samples. Other causes, such as temperature and humidity, also play important roles in the testing of sensitivity. Humidity will decrease the sensitivity and may be harmful to repeatability. The most important characteristics of these sensors are very high sensitivity, simple signal (resistance), small size, simple constitution, possibility of large-scale manufacturing in very high volumes (these sensors can be manufactured using the microelectronic and MEMS technologies), and easy integration into electronic boards. All these advantages make it a promising technology for the future. These types of sensors can be envisaged to detect polluting gases such as $\mathrm{CO}, \mathrm{SO}_{2}, \mathrm{NO}_{2}, \mathrm{O}_{3}$, fuel gases (hydrocarbon and hydrogen), toxic gases $\left(\mathrm{H}_{2} \mathrm{~S}, \mathrm{NH}_{3}\right)$, and volatile organic compounds.

Acknowledgments This research has been supported by the Universiti Sains Malaysia (USM) fellowship (APEX 91002/JHEA/ ATSG4001) and fundamental research grant scheme (FRGS) under grant number of 203/PBAHAN/6071263.

Open Access This article is distributed under the terms of the Creative Commons Attribution 4.0 International License (http://crea tivecommons.org/licenses/by/4.0/), which permits unrestricted use, distribution, and reproduction in any medium, provided you give appropriate credit to the original author(s) and the source, provide a link to the Creative Commons license, and indicate if changes were made.

\section{References}

1. M.A. Subramanian, D. Li, N. Duan, B.A. Reisner, A. Sleight, High dielectric constant in $\mathrm{ACaCu}_{3} \mathrm{Ti}_{4} \mathrm{O}_{12}$ and $\mathrm{A} \mathrm{CaCu}_{3} \mathrm{Ti}_{4} \mathrm{O}_{12}$ phases. J. Solid State Chem. 151(2), 323-325 (2000). doi:10. 1006/jssc.2000.8703

2. R. Lohnert, H. Bartsch, R. Schmidt, B. Capraro, J. Topfer, Microstructure and electric properties of $\mathrm{CaCu}_{3} \mathrm{Ti}_{4} \mathrm{O}_{12}$ multilayer capacitors. J. Am. Ceram. Soc. 98(1), 141-147 (2014). doi: $10.1111 /$ jace. 13260

3. L.C. Kretly, A.F.L. Almeida, R.S. de Oliveira, J.M. Sasaki, A.S.B. Sombra, Electrical and optical properties of $\mathrm{CaCu}_{3} \mathrm{Ti}_{4-}$ $\mathrm{O}_{12}$ (CCTO) substrates for microwave devices and antennas. Microw. Opt. Technol. Lett. 39(2), 145-150 (2003). doi:10. 1002/mop.11152

4. M.A. Ponce, M.A. Ramirez, F. Schipani, E. Joanni, J.P. Tomba, M.S. Castro, Electrical behavior analysis of n-type $\mathrm{CaCu}_{3} \mathrm{Ti}_{4} \mathrm{O}_{12}$ thick films exposed to different atmospheres. J. Eur. Ceram. Soc. 35(1), 153-161 (2015). doi:10.1016/j.jeurceramsoc.2014.08.041

5. M.A. Sulaiman, S.D. Hutagalung, M.F. Ain, Z.A. Ahmad, Dielectric properties of $\mathrm{Nb}$-doped $\mathrm{CaCu}_{3} \mathrm{Ti}_{4} \mathrm{O}_{12}$ electroceramics measured at high frequencies. J. Alloy. Compd. 493(1), 486-492 (2010). doi:10.1016/j.jallcom.2009.12.137

6. W.X. Yuan, S.K. Hark, W.N. Mei, Investigation of triple extrinsic origins of colossal dielectric constant in $\mathrm{CaCu}_{3} \mathrm{Ti}_{4} \mathrm{O}_{12}$ ceramics. J. Electrochem. Soc. 157(5), G117-G120 (2010). doi: $10.1149 / 1.3353040$

7. W.M. Hua, Z. Fu, W.Q. Li, Y. Chao, Synthesis of $\mathrm{CaCu}_{3} \mathrm{Ti}_{4} \mathrm{O}_{12}$ powders and ceramics by sol-gel method using decanedioic acid and its dielectric properties. J. Cent. South Univ. 19(12), 3385-3389 (2012). doi:10.1007/s11771-012-1418-2

8. N. Banerjee, S.B. Krupanidhi, Low temperature synthesis of nano-crystalline $\mathrm{CaCu}_{3} \mathrm{Ti}_{4} \mathrm{O}_{12}$ through a fuel mediated autocombustion pathway. Curr. Nanosci. 6(4), 432-438 (2010). doi: $10.2174 / 157341310791658955$

9. K.M. Kim, S.J. Kim, J.H. Lee, D.Y. Kim, Microstructural evolution and dielectric properties of $\mathrm{SiO}_{2}$-doped $\mathrm{CaCu}_{3} \mathrm{Ti}_{4} \mathrm{O}_{12}$ ceramics. J. Eur. Ceram. Soc. 27(13), 3991-3995 (2007). doi:10. 1016/j.jeurceramsoc.2007.02.081 
10. B. Barbier, C. Combettes, S. Guillemet-Fritsch, T. Chartier, F. Rossignol, A. Rumeaud, T. Lebey, E. Dutarde, $\mathrm{CaCu}_{3} \mathrm{Ti}_{4} \mathrm{O}_{12}$ ceramics from co-precipitation method: dielectric properties of pellets and thick films. J. Eur. Ceram. Soc. 29(4), 731-735 (2009). doi:10.1016/j.jeurceramsoc.2008.07.042

11. M.M. Ahmad, E. Al-Libidi, A. Al-Jaafari, S. Ghazanfar, K. Yamada, Mechanochemical synthesis and giant dielectric properties of $\mathrm{CaCu}_{3} \mathrm{Ti}_{4} \mathrm{O}_{12}$. Appl. Phys. A 116(3), 1299-1306 (2014). doi:10.1007/s00339-014-8224-7

12. V.P.B. Marques, A. Ries, A.Z. Simoes, M.A. Ramrez, J.A. Varela, E. Longo, Evolution of $\mathrm{CaCu}_{3} \mathrm{Ti}_{4} \mathrm{O}_{12}$ varistor properties during heat treatment in vacuum. Ceram. Int. 33(7), 1187-1190 (2007). doi:10.1016/j.ceramint.2006.04.003

13. M.A.L. Cordeiro, F.L. Souza, E.R. Leite, A.J.C. Lanfredi, Anomalous current-voltage behavior of $\mathrm{CaCu}_{3} \mathrm{Ti}_{4} \mathrm{O}_{12}$ ceramics. Appl. Phys. Lett. 93(18), 182912-182913 (2008). doi:10.1063/1. 3023061

14. W.X. Yuana, S.K. Harka, W.N. Meib, Effective synthesis to fabricate a giant dielectric-constant material $\mathrm{CaCu}_{3} \mathrm{Ti}_{4} \mathrm{O}_{12}$ via solid state reactions. J. Ceram. Process. Res. 10(5), 696-699 (2009)

15. P.R. Bueno, J.A. Varela, E. Longo, $\mathrm{SnO}_{2}, \mathrm{ZnO}$ and related polycrystalline compound semiconductors: an overview and review on the voltage-dependent resistance (non-ohmic) feature. J. Eur. Ceram. Soc. 28(3), 505-529 (2008). doi:10.1016/j.jeur ceramsoc.2007.06.011

16. I.-D. Kim, A. Rothschild, T. Hyodo, H.L. Tuller, Microsphere templating as means of enhancing surface activity and gas sensitivity of $\mathrm{CaCu}_{3} \mathrm{Ti}_{4} \mathrm{O}_{12}$ thin films. Nano Lett. 6(2), 193-198 (2006). doi:10.1021/nl051965p

17. E. Joanni, R. Savu, P.R. Bueno, E. Longo, J.A. Varela, P-Type semiconducting gas sensing behavior of nanoporous if sputtered $\mathrm{CaCu}_{3} \mathrm{Ti}_{4} \mathrm{O}_{12}$ thin films. Appl. Phys. Lett. 92(13), 132110-132113 (2008). doi:10.1063/1.2905810

18. G. Heiland, Zum Einfluss von Wasserstoff auf die elektrische leitfähigkeit von ZnO-kristallen. Zeit. Phys. 138, 459-464 (1954). doi:10.1007/BF01327362

19. A. Bielanski, J. Deren, J. Haber, Electric conductivity and catalytic activity of semiconducting oxide catalysts. Nature 179, 668-669 (1957). doi:10.1038/179668a0

20. B. Wang, Y.P. Pu, H.D. Wua, K. Chena, N. Xua, Influence of sintering atmosphere on dielectric properties and microstructure of $\mathrm{CaCu}_{3} \mathrm{Ti}_{4} \mathrm{O}_{12}$ ceramics. Ceram. Int. 39(1), S525-S528 (2013). doi:10.1016/j.ceramint.2012.10.127

21. P. Liu, Y. Lai, Y. Zeng, S. Wu, Z. Huang, J. Han, Influence of sintering conditions on microstructure and electrical properties of $\mathrm{CaCu}_{3} \mathrm{Ti}_{4} \mathrm{O}_{12}$ (CCTO) ceramics. J. Alloy. Compd. 650(59-64), 2015 (2015). doi:10.1016/j.jallcom.2015.07.247

22. S.F. Shao, J.L. Zhang, P. Zheng, W.L. Zhong, C.L. Wang, Microstructure and electrical properties of $\mathrm{CaCu}_{3} \mathrm{Ti}_{4} \mathrm{O}_{12}$ ceramics. J. Appl. Phys. 99(8), 084106-084111 (2006). doi:10. 1063/1.2191447

23. J. Liu, R.W. Smith, W.N. Mei, Synthesis of the giant dielectric constant material $\mathrm{CaCu}_{3} \mathrm{Ti}_{4} \mathrm{O}_{12}$ by wet-chemistry methods. Chem. Mater. 19(24), 6020-6024 (2007). doi:10.1021/ $\mathrm{cm} 0716553$

24. Z. Yang, Y. Zhang, R. Xiong, J. Shi, Effect of sintering in oxygen on electrical conduction and dielectric properties in $\mathrm{CaCu}_{3} \mathrm{Ti}_{4} \mathrm{O}_{12}$. Mater. Res. Bull. 48(2), 310-314 (2013). doi:10. 1016/j.materresbull.2012.10.029

25. Y. Li, P. Liang, X. Chao, Z. Yang, Preparation of $\mathrm{CaCu}_{3} \mathrm{Ti}_{4}$ $\mathrm{O}_{12}$ ceramics with low dielectric loss and giant dielectric constant by the sol-gel technique. Ceram. Int. 39(7), 7879-7889 (2013). doi:10.1016/j.ceramint.2013.03.049

26. M.H. Wang, B. Zhang, F. Zhou, Preparation and characterization of $\mathrm{CaCu}_{3} \mathrm{Ti}_{4} \mathrm{O}_{12}$ powders by non-hydrolytic sol-gel method. J. Sol-Gel. Sci. Technol. 70(1), 62-66 (2014). doi:10. 1007/s10971-014-3274-z

27. L. Laijun, F. Huiqing, F. Pinyang, C. Xiuli, Sol-gel derived $\mathrm{CaCu}_{3} \mathrm{Ti}_{4} \mathrm{O}_{12}$ ceramics: synthesis, characterization and electrical properties. Mater. Res. Bull. 43(7), 1800-1807 (2008). doi:10.1016/j.materresbull.2007.07.012

28. Z. Surowiak, M.F. Kupriyanov, D. Czekaj, Properties of nanocrystalline ferroelectric PZT ceramics. J. Eur. Ceram. Soc. 21(10), 1377-1381 (2001). doi:10.1016/S0955-2219(01)00022$\mathrm{X}$

29. H.Q. Fan, H.E. Kim, Microstructure and electrical properties of sol-gel derived $\mathrm{Pb}\left(\mathrm{Mg}_{1 / 3} \mathrm{Nb}_{2 / 3}\right)_{0.7} \mathrm{Ti}_{0.3} \mathrm{O}_{3}$ thin films with single perovskite phase. Jpn. J. Appl. Phys. 41(11B), 6768-6772 (2002). http://iopscience.iop.org/1347-4065/41/11S/6768

30. S.M. Moussa, B.J. Kennedy, Structural studies of the distorted perovskite $\mathrm{Ca}_{0.25} \mathrm{Cu}_{0.75} \mathrm{TiO}_{3}$. Mater. Res. Bull. 36(13), 2525-2529 (2001). doi:10.1016/S0025-5408(01)00732-2

31. M. Ahmadipour, K. Venkateswara Rao, V. Rajendar, Formation of nano scale $\mathrm{Mg}_{(\mathrm{x})} \mathrm{Fe}_{(1-\mathrm{x})} \mathrm{O}(\mathrm{x}=0.1,0.2,0.4)$ structure by solution combustion: effect of fuel to oxidizer ratio. J. Nanomater. 2012, 1-8 (2012). doi:10.1155/2012/163909

32. G. Xanthopoulou, Catalytic properties of the SHS products. Adv. Sci. Technol. 63, 287-296 (2010). doi:10.4028/www.sci entific.net/AST.63.287

33. A.G. Merzhanov, V.V. Barzykin, Some problems of propellant ignition. Preprint of the Institute of Chemical Physics of USSR Academy of Science, Moscow, 1970

34. E.G. Gillan, R.B. Kaner, Synthesis of refractory ceramic via rapid metathesis reactions between solid-state precursor. Chem. Mater. 8(2), 333-343 (1996). doi:10.1021/cm950232a

35. J.J. Kingsley, K.C. Patil, A novel combustion process for the synthesis of fine particle $\alpha$-alumina and related oxide materials. Mater. Lett. 6(11), 427-432 (1988). doi:10.1016/0167577X(88)90045-6

36. M. Ahmadipour, M. Hatami, K.V. Rao, Preparation and characterization of nano-sized $\left(\mathrm{Mg}_{(\mathrm{x})} \mathrm{Fe}_{(1-\mathrm{x})} \mathrm{O} / \mathrm{SiO}_{2}\right)(\mathrm{x}=0.1)$ coreshell nanoparticles by chemical precipitation method. Adv. Nanoparticles 1(3), 37-43 (2012). doi:10.4236/anp.2012.13006

37. S. Patra, Synthesis and characterization of $\mathrm{CaCu}_{3} \mathrm{Ti}_{4} \mathrm{O}_{12}$ and lanthanum doped $\mathrm{CaCu}_{3} \mathrm{Ti}_{4} \mathrm{O}_{12}$ by auto-combustion technique, Master of science thesis, Department of Ceramic Engineering National Institute of Technology, Rourkela, India, 2009

38. A. Gendaken, Sonochemistry and its application to nanochemistry. Curr. Sci. 85(12), 1720-1722 (2003)

39. N. Wongpisutpaisan, N. Vittayakorn, A. Ruangphanit, W. Pecharapa, $\mathrm{CaCu}_{3} \mathrm{Ti}_{4} \mathrm{O}_{12}$ ceramic synthesized by sonochemicalassisted process. Integr. Ferroelectr. 149(1), 56-60 (2013). doi:10.1080/10584587.2013.852936

40. D. Harvey, Modern analytical chemistry, illustrated (McGrawHill, New York, 2000), pp. 1-798

41. M.H. Whangbo, M.A. Subramanian, Structural model of planar defects in $\mathrm{CaCu}_{3} \mathrm{Ti}_{4} \mathrm{O}_{12}$ exhibiting a giant dielectric constant. Chem. Mater. 18(14), 3257-3260 (2006). doi:10.1021/ $\mathrm{cm} 060323 \mathrm{f}$

42. T.B. Adams, D.C. Sinclair, A.R. West, Characterization of grain boundary impedances in fine- and coarse-grained $\mathrm{CaCu}_{3} \mathrm{Ti}_{4}$ $\mathrm{O}_{12}$ ceramics. Phys. Rev. B 73(9), 094124-094129 (2006). doi:10.1103/PhysRevB.73.094124

43. Calcium copper tianate. http://en.wikipedia.org/wiki/Calcium copper_tianate. Accessed 18 September 2015

44. J.J. Mohamed, S.D. Hutagalung, M.F. Ain, K. Deraman, Z.A. Ahmad, Microstructure and dielectric properties of $\mathrm{CaCu}_{3} \mathrm{Ti}_{4}$ $\mathrm{O}_{12}$ ceramic. Mater. Lett. 61(8), 1835-1838 (2007). doi:10. 1016/j.matlet.2006.07.192

45. P. Fiorenza, R.L. Nigro, C. Bongiorno, V. Raineri, M.C. Ferarrelli, D.C. Sinclair, A.R. West, Localized electrical 
characterization of the giant permittivity effect in $\mathrm{CaCu}_{3} \mathrm{Ti}_{4} \mathrm{O}_{12}$ ceramics. Appl. Phys. Lett. 92(18), 182907-3 (2008). doi:10. $1063 / 1.2919095$

46. T.B. Adams, D.C. Sinclair, A.R. West, Giant barrier layer capacitance effects in $\mathrm{CaCu}_{3} \mathrm{Ti}_{4} \mathrm{O}_{12}$ ceramics. Adv. Mater. 14(18), 1321-1323 (2002). doi:10.1002/15214095(20020916) 14:18<1321:aid-adma1321>3.0.co;2-p

47. C.C. Homes, T. Vogt, S.M. Shapiro, S. Wakimoto, M.A. Subramanian, A.P. Ramirez, Charge transfer in the high dielectric constant materials $\mathrm{CaCu}_{3} \mathrm{Ti}_{4} \mathrm{O}_{12}$ and $\mathrm{CdCu}_{3} \mathrm{Ti}_{4} \mathrm{O}_{12}$. Phys. Rev. B 67(9), 092106-4 (2003). doi:10.1103/PhysRevB. 67.092106

48. I.P. Raevski, S.A. Prosandeev, A.S. Bogatin, M.A. Malitskaya, L. Jastrabik, High dielectric permittivity in $\mathrm{AFe}_{1 / 2} \mathrm{~B}_{1 / 2} \mathrm{O}_{3}$ nonferroelectric perovskite ceramics $(\mathrm{A}=\mathrm{Ba}, \mathrm{Sr}, \mathrm{Ca} ; \mathrm{B}=\mathrm{Nb}, \mathrm{Ta}, \mathrm{Sb})$. J. Appl. Phys. 93(7), 4130-4137 (2003). doi:10.1063/1.1558205

49. M.C. Ferrarelli, D.C. Sinclair, A.R. West, H.A. Dabkowska, A. Dabkowski, G.M. Luke, Comment on the origin(s) of the giant permittivity effect in $\mathrm{CaCu}_{3} \mathrm{Ti}_{4} \mathrm{O}_{12}$ single crystals and ceramics. J. Mater. Chem. 19, 5916-5919 (2009). doi:10.1039/b910871h

50. W.X. Yuan, S.K. Hark, Investigation on the origin of the giant dielectric constant in $\mathrm{CaCu}_{3} \mathrm{Ti}_{4} \mathrm{O}_{12}$ ceramics through analyzing $\mathrm{CaCu}_{3} \mathrm{Ti}_{4} \mathrm{O}_{12}-\mathrm{HfO}_{2}$ composites. J. Eur. Ceram. Soc. 32(2), 465-470 (2012). doi:10.1016/j.jeurceramsoc.2011.09.021

51. A. Deschanvres, B. Ravenau, F. Tollemer, Remplacement de metal bivalent par le cuivre dans les titanates de type perowskite. Bull. Chim. Soc. Fr. 11, 4077-4078 (1967)

52. B.A. Bender, M.J. Pan, The effect of processing on the giant dielectric properties of $\mathrm{CaCu}_{3} \mathrm{Ti}_{4} \mathrm{O}_{12}$. Mater. Sci. Eng. B 117(3), 339-347 (2005). doi:10.1016/j.mseb.2004.11.019

53. D.C. Sinclair, T.B. Adams, F.D. Morrison, A.R. West, $\mathrm{CaCu}_{3-}$ $\mathrm{Ti}_{4} \mathrm{O}_{12}$ : One-step internal barrier layer capacitor. Appl. Phys. Lett. 80(12), 2153 (2002). doi:10.1063/1.1463211

54. W.X. Yuana, Z.J. Li, Microstructures and dielectric properties of $\mathrm{CaCu}_{3} \mathrm{Ti}_{4} \mathrm{O}_{12}$ ceramics via combustion method. Eur. Phys. J. Appl. Phys. 57(1), 11302-11306 (2012). doi:10.1051/epjap/ 2011110226

55. L. Wei, X. Zhao-Xian, X. Hao, Preparation and electrical properties of $\mathrm{CaCu}_{3} \mathrm{Ti}_{4} \mathrm{O}_{12}$ thin ceramic sheets via water-based tape casting. J. Inorg. Mater. 29(11), 1228-1232 (2014). doi:10. 15541/jim20140255

56. R. Schmidt, M.C. Stennett, N.C. Hyatt, J. Pokorny, J. PradoGonjal, M. Li, D.C. Sinclair, Effects of sintering temperature on the internal barrier layer capacitor (IBLC) structure in $\mathrm{CaCu}_{3-}$ $\mathrm{Ti}_{4} \mathrm{O}_{12}$ (CCTO) ceramics. J. Eur. Ceram. Soc. 32(12), 3313-3323 (2012). doi:10.1016/j.jeurceramsoc.2012.03.040

57. J.J. Romero, P. Leret, F. Rubio-Marcos, A. Quesada, J.F. Fernández, Evolution of the intergranular phase during sintering of $\mathrm{CaCu}_{3} \mathrm{Ti}_{4} \mathrm{O}_{12}$ ceramics. J. Eur. Ceram. Soc. 30(3), 737-742 (2010). doi:10.1016/j.jeurceramsoc.2012.03.040

58. A. Rajabatabar, W.L. Li, O.S. Bishe, L.D. Wang, X.L. Li, N. Li, W.D. Fei, Effect of synthesis technique on dielectric properties of $\mathrm{CaCu}_{3} \mathrm{Ti}_{4} \mathrm{O}_{12}$ ceramic. Trans. Nonferrous Met. Soc. China 21(2), s400-s404 (2011). doi:10.1016/S1003-6326(11)61614-2

59. D.L. Sun, A.Y. Wu, S.T. Yin, Structure, properties, and impedance spectroscopy of $\mathrm{CaCu}_{3} \mathrm{Ti}_{4} \mathrm{O}_{12}$ ceramics prepared by SolGel process. J. Am. Ceram. Soc. 91(1), 169-173 (2008). doi:10. 1111/j.1551-2916.2007.02096.x

60. W.Q. Ni, X.H. Zheng, J.C. Yu, Sintering effects on structure and dielectric properties of dielectrics $\mathrm{CaCu}_{3} \mathrm{Ti}_{4} \mathrm{O}_{12}$. J. Mater. Sci. 42(3), 1037-1041 (2007). doi:10.1007/s10853-006-1431-7

61. G. Chiodellia, V. Massarotti, D. Capsoni, M. Bini, C.B. Azzoni, M.C. Mozzati, P. Lupotto, Electric and dielectric properties of pure and doped $\mathrm{CaCu}_{3} \mathrm{Ti}_{4} \mathrm{O}_{12}$ perovskite materials. Solid State Commun. 132(3), 241-246 (2004). doi:10.1016/j.ssc.2004.07. 058
62. L. Shengtao, W. Hui, L. Chunjiang, Y. Yang, L. Jianying, Dielectric properites of $\mathrm{Al}$-doped $\mathrm{CaCu}_{3} \mathrm{Ti}_{4} \mathrm{O}_{12}$ ceramics by coprecipitation method, in IEEE, conference proceedings of ISEIM, pp. 23-26, 2011. doi:10.1109/ISEIM.2011.6826267

63. S.W. Choi, S.H. Hong, Y.M. Kim, Effect of $\mathrm{Al}$ doping on the electric and dielectric properties of $\mathrm{CaCu}_{3} \mathrm{Ti}_{4} \mathrm{O}_{12}$. J. Am. Ceram. Soc. 90(12), 4009-4011 (2007). doi:10.1111/j.1551-2916.2007. 01983.x

64. S.H. Hong, D.Y. Kim, Electric and dielectric properties of Nbdoped $\mathrm{CaCu}_{3} \mathrm{Ti}_{4} \mathrm{O}_{12}$ ceramics. J. Am. Ceram. Soc. 90(7), 2118-2121 (2007). doi:10.1111/j.1551-2916.2007.01709.x

65. Y. Liu, Q. Chen, X. Zhao, Dielectric response of Sb-doped $\mathrm{CaCu}_{3} \mathrm{Ti}_{4} \mathrm{O}_{12}$ ceramics. J. Mater. Sci.: Mater. Electron. 25(3), 1547-1552 (2014). doi:10.1007/s10854-014-1766-9

66. L. Singh, U.S. Rai, Dielectric properties of ultrafine Zn-doped $\mathrm{CaCu}_{3} \mathrm{Ti}_{4} \mathrm{O}_{12}$ ceramic. J. Adv. Dielectr. 2(1), 1250007-6 (2012). doi:10.1142/S2010135X12500075

67. S.D. Hutagalung, L.Y. Ooi, Z.A. Ahmad, Improvement in dielectric properties of $\mathrm{Zn}$-doped $\mathrm{CaCu}_{3} \mathrm{Ti}_{4} \mathrm{O}_{12}$ electroceramics prepared by modified mechanical alloying technique. J. Alloy. Compd. 476(1), 477-481 (2009). doi:10.1016/j.jallcom.2008.09. 025

68. L.F. Xu, P.B. Qi, X.P. Song, X.J. Luo, C.P. Yang, Dielectric relaxation behaviors of pure and $\mathrm{Pr}_{6} \mathrm{O}_{11}$-doped $\mathrm{CaCu}_{3} \mathrm{Ti}_{4} \mathrm{O}_{12}$ ceramics in high temperature range. J. Alloy. Compd. 509(29), 7697-7701 (2011). doi:10.1016/j.jallcom.2011.02.105

69. S. Vangchangyia, T. Yamwong, E. Swatsitang, P. Thongbai, S. Maensiri, Selectivity of doping ions to effectively improve dielectric and non-ohmic properties of $\mathrm{CaCu}_{3} \mathrm{Ti}_{4} \mathrm{O}_{12}$ ceramics. Ceram. Int. 39(7), 8133-8137 (2013). doi:10.1016/j.ceramint. 2013.03.086

70. C. Mua, H. Zhang, Y. He, P. Liu, Influence of temperature on dielectric properties of $\mathrm{Fe}$ doped $\mathrm{CaCu}_{3} \mathrm{Ti}_{4} \mathrm{O}_{12}$ ceramics. Phys. B 405(1), 386-389 (2010). doi:10.1016/j.physb.2009.08.093

71. Z. Yang, Y. Zhang, G. You, K. Zhang, R. Xiong, J. Shi, Dielectric and electrical transport properties of the $\mathrm{Fe}^{3+}$-doped $\mathrm{CaCu}_{3} \mathrm{Ti}_{4} \mathrm{O}_{12}$. J. Mater. Sci. Technol. 28(12), 1145-1150 (2012). doi:10.1016/S1005-0302(12)60184-4

72. T. Li, J. Chen, D. Liu, Z. Zhang, Z. Chen, Z. Li, X.Z. Cao, B. Wang, Effect of NiO-doping on the microstructure and the dielectric properties of $\mathrm{CaCu}_{3} \mathrm{Ti}_{4} \mathrm{O}_{12}$ ceramics. Ceram. Int. 40(7), 9061-9067 (2014). doi:10.1016/j.ceramint.2014.01.119

73. X. Dong, S. Qi, Z. Ke, X.H. Xing, Y.Y. Tao, Y.R. Hong, NiOdoped $\mathrm{CaCu}_{3} \mathrm{Ti}_{4} \mathrm{O}_{12}$ thin film by sol-gel method. J. Inorg. Mater. 28(10), 1-4 (2013). doi:10.3724/SP.J.1077.2013.13113

74. V.S. Saji, H.C. Choe, Effect of yttrium doping on the dielectric properties of $\mathrm{CaCu}_{3} \mathrm{Ti}_{4} \mathrm{O}_{12}$ thin film produced by chemical solution deposition. Thin Solid Films 517(14), 3896-3899 (2009). doi:10.1016/j.tsf.2009.01.100

75. F. Luo, J. He, J. Hu, Y.H. Lin, Electric and dielectric behaviors of Y-doped calcium copper titanate. J. Am. Ceram. Soc. 93(10), 3043-3045 (2010). doi:10.1111/j.1551-2916.2010.04022.x

76. L. Shengtao, Y. Yang, W. Hui, L. Jianying, Dielectric properties of $\mathrm{B}$-doped $\mathrm{CaCu}_{3} \mathrm{Ti}_{4} \mathrm{O}_{12}$ ceramics, in IEEE, conference proceedings of ISEIM, pp. 482-485, 2011. doi:10.1109/ISEIM. 2011.6826318

77. W. Makcharoen, T. Tunkasiri, Microstructures and dielectric relaxation behaviors of pure and tellurium doped $\mathrm{CaCu}_{3} \mathrm{Ti}_{4}$ $\mathrm{O}_{12}$ ceramics prepared via vibro-milling method. Ceram. Int. 39(1), s359-s364 (2013). doi:10.1016/j.ceramint.2012.10.094

78. C. Mu, Y. Song, H. Wang, X. Wang, Room temperature magnetic and dielectric properties of cobalt doped $\mathrm{CaCu}_{3} \mathrm{Ti}_{4} \mathrm{O}_{12}$ Ceramics. J. Appl. Phys. 117, 17B723-17B724 (2015). doi:10. $1063 / 1.4916116$

79. W.L. Li, Y. Zhao, Q.G. Chi, Z.G. Zhang, W.D. Fei, Enhanced performance of core-shell-like structure $\mathrm{Zr}$-doped $\mathrm{CaCu}_{3} \mathrm{Ti}_{4} \mathrm{O}_{12}$ 
ceramics prepared by a flame synthetic approach. RSC Adv. 2(14), 6073-6078 (2012). doi:10.1039/C2RA20806G

80. Q.G. Chi, L. Gao, X. Wanga, J.Q. Lin, J. Sun, Q.Q. Lei, Effects of $\mathrm{Zr}$ doping on the microstructures and dielectric properties of $\mathrm{CaCu}_{3} \mathrm{Ti}_{4} \mathrm{O}_{12}$ ceramics. J. Alloy. Compd. 559, 45-48 (2013). doi:10.1016/j.jallcom.2013.01.090

81. J. Jumpatam, B. Putasaeng, T. Yamwong, P. Thongbai, S. Maensiri, Enhancement of giant dielectric response in Ga-doped $\mathrm{CaCu}_{3} \mathrm{Ti}_{4} \mathrm{O}_{12}$ ceramics. Ceram. Int. 39(2), 1057-1064 (2013). doi:10.1016/j.ceramint.2012.07.027

82. P. Thongbai, J. Jumpatam, B. Putasaeng, T. Yamwong, V. Amornkitbamrung, S. Maensiri, Effects of $\mathrm{La}^{3+}$ doping ions on dielectric properties and formation of Schottky barriers at internal interfaces in a $\mathrm{Ca}_{2} \mathrm{Cu}_{2} \mathrm{Ti}_{4} \mathrm{O}_{12}$ composite system. J. Mater. Sci.: Mater. Electron. 25(10), 4657-4663 (2014). doi:10.1007/s10854-014-2219-1

83. S. Jin, H. Xia, Y. Zhang, Effect of La-doping on the properties of $\mathrm{CaCu}_{3} \mathrm{Ti}_{4} \mathrm{O}_{12}$ dielectric ceramics. Ceram. Int. 35(1), 309-313 (2009). doi:10.1016/j.ceramint.2007.10.007

84. W. Li, S. Qiu, N. Chen, G. Du, Enhanced dielectric response in $\mathrm{Mg}$-doped $\mathrm{CaCu}_{3} \mathrm{Ti}_{4} \mathrm{O}_{12}$ ceramics. J. Mater. Sci. Technol. 26(8), 682-686 (2010). doi:10.1016/S1005-0302(10)60107-7

85. J. Li, B. Fu, H. Lu, C. Huang, J.W. Sheng, Dielectric properties of Sm-doped $\mathrm{CaCu}_{3} \mathrm{Ti}_{4} \mathrm{O}_{12}$ ceramics. Ceram. Int. 39(1), s149s152 (2013). doi:10.1016/j.ceramint.2012.10.052

86. M. Li, A. Feteira, D.C. Sinclair, A.R. West, Influence of Mn doping on the semiconducting properties of $\mathrm{CaCu}_{3} \mathrm{Ti}_{4} \mathrm{O}_{12}$ ceramics. Appl. Phys. Lett. 88(23), 232903 (2006). doi:10.1063/1.2200732

87. C.H. Kim, Y.H. Jang, S.J. Seo, C.H. Song, J.Y. Son, Y.S. Yang, J.H. Cho, Effect of Mn doping on the temperature-dependent anomalous giant dielectric behavior of $\mathrm{CaCu}_{3} \mathrm{Ti}_{4} \mathrm{O}_{12}$. Phys. Rev. B 85(24), 245210-245216 (2012). doi:10.1103/PhysRevB.85.245210

88. K. Meeporn, T. Yamwong, S. Pinitsoontorn, V. Amornkitbamrung, $\mathrm{P}$. Thongbai, Grain size independence of giant dielectric permittivity of $\mathrm{CaCu}_{3} \mathrm{Ti}_{4-\mathrm{x}} \mathrm{Sc}_{\mathrm{x}} \mathrm{O}_{12}$ ceramics. Ceram. Int. 40(10), 15897-15906 (2014). doi:10.1016/j.ceramint.2014.07.118

89. P. Thongbai, S. Vangchangyia, E. Swatsitang, V. Amornkitbamrung, T. Yamwong, S. Maensiri, Non-Ohmic and dielectric properties of Ba-doped $\mathrm{CaCu}_{3} \mathrm{Ti}_{4} \mathrm{O}_{12}$ ceramics. J. Mater. Sci.: Mater. Electron. 24(3), 875-883 (2013). doi:10.1007/s10854012-0842-2

90. Z. Xu, H. Qiang, Z. Chen, Y. Chen, Dielectric behavior of Badoped $\mathrm{CaCu}_{3} \mathrm{Ti}_{4} \mathrm{O}_{12}$ ceramics prepared from citrate-nitrate combustion derived powders. J. Mater. Sci.: Mater. Electron. 26(1), 578-582 (2015). doi:10.1007/s10854-014-2437-6

91. W. Si, E.M. Cruz, P.D. Johnson, P.W. Barnes, P. Woodward, A.P. Ramirez, Epitaxial thin films of the giant-dielectric-constant material grown by pulsed-laser deposition. Appl. Phys. Lett. 81(11), 2056-2058 (2002). doi:10.1063/1.1506951

92. K. Cho, N. Wu, A. Ignatiev, Dielectric properties of $\mathrm{CaCu}_{3-}$ $\mathrm{Ti}_{4} \mathrm{O}_{12}$ thin films, in Isaf 2002: proceedings of the 13th IEEE international symposium on applications of ferroelectrics, pp. 187-190, 2002. doi:10.1109/ISAF.2002.1195901

93. J.R. Li, Dielectric characterization of polycrystalline and epitaxial thin film $\mathrm{CaCu}_{3} \mathrm{Ti}_{4} \mathrm{O}_{12}$ (CCTO), in Proceedings of the 7 th international conference on properties and applications of dielectric materials, vol. 3, pp. 1096-1099, 2003. doi:10.1109/ ICPADM.2003.1218614

94. L. Fang, M.R. Shen, Deposition and dielectric properties of $\mathrm{CaCu}_{3} \mathrm{Ti}_{4} \mathrm{O}_{12}$ thin films on $\mathrm{Pt} / \mathrm{Ti} / \mathrm{SiO}_{2} / \mathrm{Si}$ substrates using pulsed-laser deposition. Thin Solid Films 440(1), 60-65 (2003). doi:10.1016/S0040-6090(03)00825-3

95. Y.L. Zhao, G.W. Pan, Q.B. Ren, Y.G. Cao, L.X. Feng, Z.K. Jiao, High dielectric constant in $\mathrm{CaCu}_{3} \mathrm{Ti}_{4} \mathrm{O}_{12}$ thin film prepared by pulsed laser deposition. Thin Solid Films 445(1), 7-13 (2003). doi:10.1016/S0040-6090(03)00666-7
96. G. Deng, T. Yamada, P. Muralt, Evidence for the existence of a metal-insulator-semiconductor $\mathrm{CaCu}_{3} \mathrm{Ti}_{4} \mathrm{O}_{12}$ junction at the electrode interfaces of thin film capacitors. Appl. Phys. Lett. 91(20), 202903-3 (2007). doi:10.1063/1.2814043

97. B.S. Prakash, K. Varma, D. Michau, M. Maglione, Deposition and dielectric properties of $\mathrm{CaCu}_{3} \mathrm{Ti}_{4} \mathrm{O}_{12}$ thin films deposited on $\mathrm{Pt} / \mathrm{Ti} / \mathrm{SiO}_{2} / \mathrm{Si}$ substrates using radio frequency magnetron sputtering. Thin Solid Films 516(10), 2874-2880 (2008). doi:10. 1016/j.tsf.2007.05.060

98. R.L. Nigro, R.G. Toro, G. Malandrino, I.L. Fragalà, P. Fiorenza, V. Raineri, Effects of high temperature annealing on MOCVD grown $\mathrm{CaCu}_{3} \mathrm{Ti}_{4} \mathrm{O}_{12}$ films on $\mathrm{LaAlO}_{3}$ substrates. Surf. Coat. Technol. 201(22), 9243-9247 (2007). doi:10.1016/j.surfcoat. 2007.05.019

99. R.L. Nigro, R.G. Toro, G. Malandrino, I.L. Fragalà, P. Fiorenza, V. Raineri, Chemical stability of $\mathrm{CaCu}_{3} \mathrm{Ti}_{4} \mathrm{O}_{12}$ thin films grown by MOCVD on different substrates. Thin Solid Films 515(16), 6470-6473 (2007). doi:10.1016/j.tsf.2006.11.050

100. S. Jin, H. Xia, Y. Zhang, J. Guo, J. Xu, Synthesis of $\mathrm{CaCu}_{3-}$ $\mathrm{Ti}_{4} \mathrm{O}_{12}$ ceramic via a sol-gel method. Mater. Lett. 61(6), 1404-1407 (2007). doi:10.1016/j.matlet.2006.07.041

101. L. Feng, Y. Wang, Y. Yan, G. Cao, Z. Jiao, Growth of highlyoriented $\mathrm{CaCu}_{3} \mathrm{Ti}_{4} \mathrm{O}_{12}$ thin films on $\mathrm{SrTiO}_{3}\left(\begin{array}{lll}1 & 0 & 0\end{array}\right)$ substrates by a chemical solution route. Appl. Surf. Sci. 253(4), 2268-2271 (2006). doi:10.1016/j.apsusc.2006.04.029

102. D. Maurya, D.P. Singh, D.C. Agrawal, Y.N. Mohapatra, Preparation of high dielectric constant thin films of $\mathrm{CaCu}_{3} \mathrm{Ti}_{4}$ $\mathrm{O}_{12}$ by sol-gel. Bull. Mater. Sci. 31(1), 55-59 (2008). doi:10. 1007/s12034-008-0010-8

103. M. Smith, A.F. Turner, Vacuum deposited thin films using a ruby laser. Appl. Opt. 4(1), 147-148 (1965). doi:10.1364/AO.4.000147

104. L. Fang, M.R. Shen, Z.Y. Li, Effect of double-sided $\mathrm{CaTiO}_{3}$ buffer layers on the electrical properties of $\mathrm{CaCu}_{3} \mathrm{Ti}_{4} \mathrm{O}_{12}$ films on $\mathrm{Pt} / \mathrm{Ti} / \mathrm{SiO}_{2} / \mathrm{Si}$ substrates. J. Appl. Phys. 100(10), 104101-104105 (2006). doi:10.1063/1.2374952

105. L. Fang, M. Shen, J. Yang, Z. Li, Reduced dielectric loss and leakage current in $\mathrm{CaCu}_{3} \mathrm{Ti}_{4} \mathrm{O}_{12} / \mathrm{SiO}_{2} / \mathrm{CaCu}_{3} \mathrm{Ti}_{4} \mathrm{O}_{12}$ multilayered films. Solid State Commun. 137(7), 381-386 (2006). doi:10.1016/j.ssc.2005.12.004

106. P. Fiorenza, R.L. Nigro, A. Sciuto, P. Delugas, V. Raineri, R.G. Toro, M.R. Catalano, G. Malandrino, Perovskite $\mathrm{CaCu}_{3} \mathrm{Ti}_{4} \mathrm{O}_{12}$ thin films for capacitive applications: from the growth to the nanoscopic imaging of the permittivity. J. Appl. Phys. 105(1), 061634-061636 (2009). doi:10.1063/1.3086198

107. R. Jiménez, M.L. Calzada, I. Bretos, J.C. Goes, A.S.B. Sombra, Dielectric properties of sol-gel derived $\mathrm{CaCu}_{3} \mathrm{Ti}_{4} \mathrm{O}_{12}$ thin films onto $\mathrm{Pt} / \mathrm{TiO}_{2} / \mathrm{Si}\left(\begin{array}{lll}1 & 0 & 0\end{array}\right)$ substrates. J. Eur. Ceram. Soc. 27(13), 3829-3833 (2007). doi:10.1016/j.jeurceramsoc.2007.02.050

108. Y.S. Shen, B.S. Chiou, C.C. Ho, Effects of annealing temperature on the resistance switching behavior of $\mathrm{CaCu}_{3} \mathrm{Ti}_{4} \mathrm{O}_{12}$ films. Thin Solid Films 517(3), 1209-1213 (2008). doi:10.1016/j.tsf. 2008.06.034

109. Y.W. Li, Z.G. Hu, J.L. Sun, X.J. Meng, J.H. Chu, Preparation and properties of $\mathrm{CaCu}_{3} \mathrm{Ti}_{4} \mathrm{O}_{12}$ thin film grown on $\mathrm{LaNiO}_{3}$ coated silicon by sol-gel process. J. Cryst. Growth 310(2), 378-381 (2008). doi:10.1016/j.jcrysgro.2007.11.025

110. Y.W. Li, Y.D. Shen, Z.G. Hu, F.Y. Yue, J.H. Chu, Effect of thickness on the dielectric property and nonlinear current-voltage behavior of $\mathrm{CaCu}_{3} \mathrm{Ti}_{4} \mathrm{O}_{12}$ thin films. Phys. Lett. A 373(27), 2389-2392 (2009). doi:10.1016/j.physleta.2009.05.001

111. W.H. Brattain, J. Bardeen, Surface properties of germanium. Bell Syst. Tech. J. 32(1), 1-41 (1953). doi:10.1002/j.1538-7305. 1953.tb01420.x

112. T. Seiyama, A. Kato, K. Fujiishi, M. Nagatani, A new detector for gaseous components using semiconductive thin films. Anal. Chem. 34(11), 1502-1503 (1962). doi:10.1021/ac60191a001 
113. E. Kanazawa, G. Sakai, K. Shimanoe, Y. Kanmura, Y. Teraoka, N. Miura, N. Yamazoe, Metal oxide semiconductor $\mathrm{N}_{2} \mathrm{O}$ sensor for medical use. Sens. Actuators B: Chem. 77(1), 72-77 (2001). doi:10.1016/S0925-4005(01)00675-X

114. P.T. Moseley, Solid state gas sensors. Meas. Sci. Technol. 8(3), 223-237 (1997)

115. S. Sekimoto, H. Nakagawa, S. Okazaki, K. Fukuda, S. Asakura, T. Shigemori, S.A. Takahashi, Fibre-optic evanescent-wave hydrogen gas sensor using palladium-supported tungsten oxide. Sens. Actuators B: Chem. 66(1), 142-145 (2000). doi:10.1016/ S0925-4005(00)00330-0

116. F. Morazzoni, R. Scotti, L. Origoni, M.D. Arienzo, I. Jimenez, A. Cornet, J.R. Morante, Mechanism of $\mathrm{NH}_{3}$ interaction with transition metal-added nanosized $\mathrm{WO}_{3}$ for gas sensing: in situ electron paramagnetic resonance study. Catal. Today 12(1), 169-176 (2006). doi:10.1016/j.cattod.2006.09.035

117. K.J. Albert, N.S. Lewis, C.L. Schauer, G.A. Sotzing, S.E. Stilzel, T.P. Vaid, D.R. Walt, Cross-reactive chemical sensor arrays. Chem. Rev. 100(7), 2595-2626 (2000). doi:10.1021/cr980102w

118. Y. Shimizu, M. Egashira, Basic aspects and challenges of semiconductor gas sensors. MRS Bull. 24(6), 18-24 (1999). doi: $10.1557 /$ S0883769400052465

119. G. Martinelli, M.C. Carotta, E. Traversa, G. Ghiotti, Thick-film gas sensors based on nanosized semiconducting oxide powders. MRS Bull. 24(6), 30-36 (1999). doi:10.1557/S0883769400052489

120. A.A. Tomchenko, G.P. Harmer, B.T. Marquis, Detection of chemical warfare agents using nanostructured metal oxide sensors. Sens. Actuators B: Chem. 108(1), 41-55 (2005). doi:10. 1016/j.snb.2004.11.059

121. A.A. Tomchenko, G.P. Harmer, B.T. Marquis, J.W. Allen, Semiconducting metal oxide sensor array for the selective detection of combustion gases. Sens. Actuators B: Chem. 93(1), 126-134 (2003). doi:10.1016/S0925-4005(03)00240-5

122. M.E. Franke, T.J. Koplin, U. Simon, Metal and metal oxide nanoparticles in chemiresistors: does the nanoscale matter. Small 2(1), 36-50 (2006). doi:10.1002/smll.200500261

123. N. Yamazoe, New approaches for improving semiconductor gas sensors. Sens. Actuators B: Chem. 5(1), 17-19 (1991). doi:10. 1016/0925-4005(91)80213-4

124. H.T. Macholdt, R. Vaneldik, High pressure effects on ligand substitution reactions of molybdenum( 0 ) carbonyl complexes. Transit. Met. Chem. 10(9), 323-325 (1985). doi:10.1021/ ic00193a042

125. G. Magner, M. Savy, G. Scarbeck, J. Riga, J.J. Verbist, Effects of substitution of iron by molybdenum in the naphthalocyanine structures upon their electrocatalytic properties for $\mathrm{O} 2$ reduction and evolution in alkaline media. J. Electrochem. Soc. 128(8), 1674-1680 (1981). doi:10.1149/1.2127709

126. I. Simon, N. Bârsan, M. Bauer, U. Weimar, Micromachined metal oxide gas sensors: opportunities to improve sensor performance. Sens. Actuators B: Chem. 73(1), 1-26 (2001). doi:10. 1016/S0925-4005(00)00639
127. M. Li, X.L. Chen, D.F. Zhang, W.Y. Wang, W.J. Wang, Humidity sensitive properties of pure and $\mathrm{Mg}$-doped $\mathrm{CaCu}_{3-}$ $\mathrm{Ti}_{4} \mathrm{O}_{12}$. Sens. Actuators B: Chem. 147(2), 447-452 (2010). doi:10.1016/j.snb.2010.03.063

128. L.J. Miao, J.W. Xin, Z.Y. Shen, Y.J. Zhang, H.Y. Wang, A.G. Wub, Exploring a new rapid colorimetric detection method of $\mathrm{Cu}^{2+}$ with high sensitivity and selectivity. Sens. Actuators B: Chem. 176, 906-912 (2013). doi:10.1016/j.snb.2012.10.070

129. M. Stankova, X. Vilanova, J. Calderer, E. Llobet, J. Brezmes, I. Gracia, C. Cane, X. Correig, Sensitivity and selectivity improvement of $\mathrm{rf}$ sputtered $\mathrm{WO}_{3}$ microhotplate gas sensors. Sens. Actuators B: Chem. 113(1), 241-248 (2006). doi:10.1016/ j.snb.2005.02.056

130. X.T. Yin, X.M. Guo, Selectivity and sensitivity of Pd-loaded and Fe-doped $\mathrm{SnO}_{2}$ sensor for CO detection. Sens. Actuators B: Chem. 200, 213-218 (2014). doi:10.1016/j.snb.2014.04.026

131. S. Yang, Y. Liu, W. Chen, W. Jin, J. Zhou, H. Zhang, G.S. Zakharova, High sensitivity and good selectivity of ultralong $\mathrm{MoO}_{3}$ nanobelts for trimethylamine gas. Sens. Actuators B: Chem. 226, 478-485 (2016). doi:10.1016/j.snb.2015.12.005

132. M. Wang, L. Zhu, C. Zhang, G. Gai, X. Ji, B. Li, Y. Yao, Lanthanum oxide@ antimony-doped tin oxide with high gas sensitivity and selectivity towards ethanol vapor. Sens. Actuators B: Chem. 224, 478-484 (2016). doi:10.1016/j.snb.2015.10. 083

133. S.Y. Chung, I.L.D. Kim, S.J.L. Kang, Strong nonlinear currentvoltage behaviour in perovskite-derivative calcium copper titanate. Nat. Mater. 3, 774-778 (2004). doi:10.1038/nmat1238

134. R. Parra, R. Savu, L.A. Ramajo, M.A. Ponce, J.A. Varela, M.S. Castro, P.R. Bueno, E. Joanni, Sol-gel synthesis of mesoporous $\mathrm{CaCu}_{3} \mathrm{Ti}_{4} \mathrm{O}_{12}$ thin films and their gas sensing response. J. Solid State Chem. 183(6), 1209-1214 (2010). doi:10.1016/j.jssc.2010. 03.033

135. E. Zampetti, S. Pantalei, A. Pecora, A. Valletta, L. Maiolo, A. Minotti, A. Macagnano, G. Fortunato, A. Bearzotti, Design and optimization of an ultra thin flexible capacitive humidity sensor. Sens. Actuators B: Chem. 143(1), 302-307 (2009). doi:10.1016/ j.snb.2009.09.004

136. J. Kim, K. Yong, Mechanism Study of ZnO Nanorod-Bundle Sensors for $\mathrm{H}_{2} \mathrm{~S}$ Gas Sensing. J. Phys. Chem. 115(15), 7218-7224 (2011). doi:10.1021/jp110129f

137. F. Mohammadzadeh, M. Jahanshahi, A.M. Rashidi, Preparation of nanosensors based on organic functionalized MWCNT for $\mathrm{H}_{2} \mathrm{~S}$ detection. Appl. Surf. Sci. 259, 159-165 (2012). doi:10. 1016/j.apsusc.2012.07.011

138. R. Nisha, K.N. Madhusoodanan, T.V. Vimalkumar, K.P. Vijayakumar, Gas sensing application of nanocrystalline zinc oxide thin films prepared by spray pyrolysis. Bull. Mater. Sci. 38(3), 583-591 (2015). doi:10.1007/s12034-015-0911-2 